\title{
Structural organization and functional divergence of high isoelectric point a-amylase genes in bread wheat (Triticum aestivum L.) and barley (Hordeum vulgare L.)
}

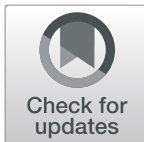

Liangliang Ju ${ }^{1,2}$, Guangbing Deng ${ }^{1}$, Junjun Liang ${ }^{1}$, Haili Zhang ${ }^{1}$, Qiao Lii ${ }^{1}$ Zhifen Pan ${ }^{1 *}$, Maoqun Yu ${ }^{1 *}$ and Hai Long ${ }^{1 *}$

\begin{abstract}
Background: High isoelectric point a-amylase genes (Amy1) play major roles during cereal seed germination, and are associated with unacceptable high residual a-amylase activities in ripe wheat grains. However, in wheat and barley, due to extremely high homology of duplicated copies, and large and complex genome background, the knowledge on this multigene family is limited.

Results: In the present work, we identified a total of 41 Amy 1 genes among 13 investigated grasses. By using genomic resources and experimental validation, the exact copy numbers and chromosomal locations in wheat and barley were determined. Phylogenetic and syntenic analyses revealed tandem gene duplication and chromosomal rearrangement leading to separation of Amy 1 into two distinct loci, Amy $1 \theta$ and $A m y 1 \lambda$. The divergence of Amy $1 \lambda$ from Amy $1 \theta$ was driven by adaptive selection pressures performed on two amino acids, $\operatorname{Arg}_{97}$ and $\operatorname{Asn}_{233}(P>0$. $95^{*}$ ). The predicted protein structural alteration caused by substitution of $\mathrm{Asp}_{233} \mathrm{Asn}$ in the conserved starch binding surface site, and significantly expressional differentiation during seed germination and grain development provided evidence of functional divergence between Amy $1 \theta$ and Amy $1 \lambda$ genes. We screened out candidate copies (TaAmy1A1/A2 and TaAmy1-D1) associated with high residual a-amylase activities in ripe grains. Furthermore, we proposed an evolutionary model for expansion dynamics of Amy 1 genes.

Conclusions: Our study provides comprehensive analyses of the Amy 1 multigene family, and defines the fixation of two spatially structural Amy 1 loci in wheat and barley. Potential functional divergence between them is reflected by their sequence features and expressional patterns, and driven by gene duplication, chromosome rearrangement and natural selections during gene family evolution. Furthermore, the discrimination of differentially effective copies during seed germination and/or grain development will provide guidance to manipulation of a-amylase activity in wheat and barley breeding for better yield and processing properties.
\end{abstract}

Keywords: a-Amylase, Isoelectric point, Gene duplication, Chromosomal rearrangement, Functional divergence

\footnotetext{
* Correspondence: panzf@cib.ac.cn; yumq@cib.ac.cn; hailong@cib.ac.cn

${ }^{1}$ Chengdu Institute of Biology, Chinese Academy of Sciences, Chengdu

610041, China

Full list of author information is available at the end of the article
}

(c) The Author(s). 2019 Open Access This article is distributed under the terms of the Creative Commons Attribution 4.0 International License (http://creativecommons.org/licenses/by/4.0/), which permits unrestricted use, distribution, and reproduction in any medium, provided you give appropriate credit to the original author(s) and the source, provide a link to the Creative Commons license, and indicate if changes were made. The Creative Commons Public Domain Dedication waiver (http://creativecommons.org/publicdomain/zero/1.0/) applies to the data made available in this article, unless otherwise stated. 


\section{Background}

Alpha-amylase ( $\alpha$-D-1,4-glucan-4-glucanohydrolases, EC 3.2.1.1) is of critical importance to the breakdown of starch granules during seed germination [1-5]. It catalyzes the hydrolysis of internal $\alpha-D$-1,4-glucosidic linkages in large polysaccharides to yield maltose and maltodextrin products [6]. In cereal crops, such as bread wheat and barley, two main isoforms of $\alpha$-amylases have been extensively investigated during seed germination or in the gibberellic acid $\left(\mathrm{GA}_{3}\right)$-induced aleurone layers [1$5]$. They were conserved in the biosynthesis and secretion from the scutellar epithelium and the aleurone layer to the starchy endosperm [7, 8]. Major differences in physicochemical and biochemical properties (i.e., sensitivity to $\mathrm{Ca}^{2+}$, stability at low $\mathrm{pH}$ and under heat treatment, and charge and serological characteristics) could be used to distinguish the two isoforms, which were eventually classified as high-pI and low-pI isoforms on the basis of isoelectric point (pI). The nomenclatures of high-pI and low-pI isoforms have not been consistent in the literature. In most of the literatures [9-12], researchers assigned high-pI and low-pI $\alpha$-amylases as symbols of $\alpha$-Amy-1 (Amy1) and $\alpha$-Amy-2 (Amy2), respectively. Oppositely, some other literatures separately designated them as Amy2 and Amy1 [13-15]. Meanwhile, some authors $[16,17]$ named low-pI isoform as type A and high-pI as type B. In this work, we are prone to adopt high-pI $\alpha$-amylase as Amy1 and low-pI as Amy2.

High-pI isoform (Amy1) was triggered by the commencement of seed germination and produced in higher concentration than that of low-pI $\alpha$-amylase (Amy2), which was characterized by its synthesis both in kernel development and during seed germination [18]. Protein crystal structures of Amy1 and Amy2 were very similar, each consisting of three domains: a central conserved $(\beta / \alpha)_{8}$-barrel domain (domain $\left.\mathrm{A}\right)$, an additional domain $B$ nested between $\beta_{3}$ and $\alpha_{3}$ of domain $A$, and a five-stranded $\mathrm{C}$-terminal $\beta$-sheet domain (domain $\mathrm{C}$ ) $[14,15,19]$. Substrate binding analysis revealed a starch granule binding surface site (SBS1) and a highly conserved active site in both of them among cereal grains, and when replaced by thio-maltotetraose as substrate analogues, a new Amy2-specific surface binding site at domain $C$ had been discovered $[15,20]$. Additionally, a novel wheat $\alpha$-amylase (TaAMY3) was reported and considered as the most abundant isoform compared with the other known $\alpha$-amylases throughout grain development $[21,22]$. The newly described isoform HvAMY4 did not subject any predicted transit peptide and detected in various plant tissues [23]. Therefore, these four categories of $\alpha$-amylases seem to accomplish starch degradations in different developmental stages or in various plant tissues, although their controlling and digesting mechanisms are still unclear. Accordingly, in cereal crops, genes encoding $\alpha$-amylases have been divided into three or four subfamilies, i.e., TaAMY1 to TaAMY3 in bread wheat [12], $H v A M Y 1$ to $H v A M Y 4$ in barley [23] and $O s A M Y 1$ to $O s A M Y 3$ in rice [12]. Recently, $A M Y 4$ genes have been identified and added to wheat and barley $[24,25]$.

Because of functional importance to the transition from dormancy to germinating, and its association with high residual $\alpha$-amylase activities in ripe wheat grains, Amy1 genes have been of interest to plant biologists for many years. This structural locus was located on the long arms of chromosomes $6 \mathrm{~A}, 6 \mathrm{~B}$ and $6 \mathrm{D}$ in bread wheat [10], and $6 \mathrm{H}$ in barley [26], respectively. It was thought to be complicated, compound and multigenetic, either consisting of tightly linked copies or involving some degree of gene duplications [4, 10]. As a self-pollination plant, bread wheat (AABBDD) is a product of at least two rounds of polyploidization, consisting three closely related diploid progenitors: T. urartu (A genome), Aegilops speltoides-related species (B genome) and Ae. tauschii (D genome) [27, 28]. The redundancy afforded by the hexaploid nature of bread wheat also increases difficulties to fully evaluate this structural locus. Based on simultaneous studies of polyacrylamide gel electrophoresis (PAGE), isoelectric focusing (IEF) and restriction fragment length polymorphism (RFLP), three Amy1 copies, located on the chromosome 6R, were determined in the diploid genome of rye [29]. Khursheed and Rogers cloned two types of barley $\alpha$-amylase genes (Amy6-4 and Amy46) belonging to the high-pI multigene family, and confirmed their different mRNA levels in the $\mathrm{GA}_{3}$-induced aleurone cells [30]. In addition, functional analysis of the Amy6-4 promoter region indicated that the gibberellic acid response elements (GARE) was comprised of three conserved cis-acting boxes ('pyrimidine' box, 'taacaaac' box and 'tatccac/t' box) [31, 32]. Through binding to the central element ('taacaaac' box), the $\mathrm{GA}_{3}$-regulated transcription factor (GAMyb) activated transcription of $A m y 1$ genes [33]. In rice, the $R A m y 1$ subfamily (RAmy1A, RAmy1B and $R A m y 1 C$ ) consists of genes corresponding to the $A m y 1$ classes of barley and wheat [12]. RAmy1A (AmyI-1) transcript was most abundant in germinating seeds and involved in the degradation of plastid starch granules [34, 35]. Recently, as reviewed by Mares and Mrva [36], pre-harvest sprouting (PHS) and late maturity $\alpha$-amylase (LMA) were characterized by high levels of $\alpha$-amylases in ripe wheat grains. Wheat lines with abnormal accumulation of $\alpha$-amylases lowered whole meal falling numbers and resulted in reduced starch viscosity and poor flour quality [36-38]. Yang et al. [39] and Cheng et al. [40] isolated Amy1 genes involved in PHS-affected and LMA-affected lines, and detected high expression of $A m y 1$ genes was 
strongly correlated with high levels of high-pI $\alpha$-amylases.

Despite considerable progresses have been made in understanding the characteristics of Amy1 genes, to date, comprehensive analysis focusing on this multigene family still lacks. It has been well established that three major grass subfamilies (Pooideae, Ehrhartoideae and Panicoideae) evolve from a common ancestral cereal genome with a basic number of five chromosomes [41, 42]. Together with recently released genome datasets of hexaploid wheat and barley, this inner circle model facilitates access to investigate the conserved block carrying this structural locus with multiple high-homology gene members, and help us to better explore their structural organization and expansion dynamics. Therefore, elucidating functional diversification of duplicated copies of this multigene family is needed for further practices of agronomic traits improvement and molecular design breeding.

In this paper, we firstly estimate the exact copy number of Amy1 genes in grass. Then, we reconstruct the phylogeny and investigate structural organization. For further exploring evolutionary forces and understanding functional implications, we conduct potential natural selection tests, build three-dimensional (3D) protein homology structures, and quantify the expression profiles in depth from copy-specific levels.

\section{Methods}

\section{Plant materials and tissue sampling}

Chinese Spring (CS) (T. aestivum) and six nullisomic-tetrasomic (NT) lines for the homoeologous group 6, PI428191 (T. urartu), PI542268 (Ae. speltoides) and AS2404 (Ae. tauschii) were used for DNA extraction and cloning experiments; seeds were incubated at room temperature for 5 to 7 days under darkness condition. Based on preliminary phenotyping under three different field conditions (Sichuan shuangliu in 2014/2015, Sichuan shifang and Yunnan yuanmou in 2014/2015), three wheat cultivars (Guinong19, Mianmai43 and Jinan17) with high residual $\alpha$-amylase activities in ripe grains and the absence of sprouting, and three landraces (Honghuamai, Siqiangxiaomai and Guangguangtou) with extreme low activities were selected for measurement of total $\alpha$-amylase activities and preparation of mRNA in the developing grains. Spikes were tagged at anthesis and sampled at 10,12,14, 16, 18, 20, 22, 24, 26, 28, 30, 32, 34 and 36 days post anthesis (DPA) in Sichuan shuangliu from late-March to early-May in 2016. For germination sampling, seeds of bread wheat (cv. CS) and barley (cv. Morex) were incubated on a moist filter paper in petri dishes under darkness condition $\left(25^{\circ} \mathrm{C}\right)$; similar seedlings were collected at $12,24,36,48 \mathrm{~h}$ (h) after seed imbibition. During growth, field management followed normal field operations. The plant materials used in the study are held in our own lab.

\section{Identification of Amy1 genes in grass}

Two approaches (molecular cloning and in silico analysis) were used to identify Amy1 genes. Firstly, the public available Amy1 sequences were collected from databases of bread wheat and other Triticeae species (https://urgi.versailles.inra.fr/blast/). To detect the TaAmy1 copy number, primer pair TaAmy1-F/R was developed for cloning the full-length genomic sequences. Total genomic DNA was extracted following the cetyl trimethylammonium bromide (CTAB) method with minor modifications. PCR products were purified and sequenced using the same forward and reverse primers at Sangon Biotech (Shanghai, China). Due to limited Taq-polymerase fidelity, clones with sub-optimal quality were discarded for further analysis.

Two barley Amy1 genes, Amy6-4 (GenBank accession no. K02637) and Amy46 (GenBank accession no. J04202) [30], were employed as query sequences to blast against the genomes of bread wheat (IWGSC WGA v0.4, https://urgi.versailles.inra.fr/blast_iwgsc/), barley (http:// webblast.ipk-gatersleben.de/), rice (http://rice.plantbiolo gy.msu.edu/) and other grasses (https://phytozome.jgi. doe.gov/) with default setting parameters. BLAST hits with an expectancy value (E-value) of zero were subjected to the second round of BLAST searches within the genomes from which they were identified. All the retrieved and cloned $A m y 1$ gene sequences were aligned with Clustal X 2.0 [43] and manually modified with BioEdit v7.2 [44]. Exons and introns were positioned by aligning full genomic sequences and their corresponding coding sequences, and visualized by the GSDS 2.0 server [45]. The $\mathrm{pI}$ values of putative amino acids were calculated using online computation tool (http://web.ex pasy.org/compute_pi/). Subcellular localization and cleavage site prediction were performed using the CBS TargetP software [46, 47].

\section{Phylogenetic reconstruction and positive selection detection}

Full-length coding sequences were used for phylogenetic analysis. Maximum likelihood trees were constructed by MEGA7 software [48] using the Tamura 3-parameter + GAMMA substitution model [49], the best fitting model as determined by the "Find Best DNA/Protein Models" function in MEGA7. All positions containing gaps and missing data were eliminated. Branch supports attached to each node were inferred from 1000 bootstrap replicates and values less than $75 \%$ were collapsed. Putative amino acids were used for estimating the genetic distance of Amy1 genes as described by Jones et al. [50]. Synonymous (Ks) and non-synonymous (Ka) substitution rates of 
Table 1 Summary information of Amyl genes identified in grass species

\begin{tabular}{|c|c|c|c|c|c|c|c|}
\hline \multirow[t]{2}{*}{ Species } & \multirow[t]{2}{*}{ Gene name } & \multirow{2}{*}{$\begin{array}{l}\text { gDNA } \\
\text { (bp) }\end{array}$} & \multirow[t]{2}{*}{$\mathrm{Chr}^{\mathrm{d}}$} & \multirow{2}{*}{$\begin{array}{l}\text { Protein } \\
\text { (aa) }\end{array}$} & \multirow[t]{2}{*}{$\mathrm{pl}$} & \multicolumn{2}{|c|}{ TargetP prediction } \\
\hline & & & & & & $\overline{S P^{e}}$ & TPlen $^{\dagger}$ \\
\hline \multirow[t]{12}{*}{ Triticum aestivum (CS) ${ }^{a}$} & TaAmy1-A1 ${ }^{\mathrm{b}}$ & 1472 & $6 \mathrm{~A}$ & 427 & 5.83 & 0.994 & 24 \\
\hline & TaAmy1-A2 $2^{b}$ & 1470 & $6 \mathrm{~A}$ & 427 & 6.00 & 0.995 & 24 \\
\hline & TaAmy1-A3 & 1773 & $6 \mathrm{~A}$ & 427 & 5.84 & 0.993 & 24 \\
\hline & TaAmy1-B1 $1^{b}$ & 1475 & $6 B$ & 427 & 5.92 & 0.990 & 24 \\
\hline & TaAmy1-B2 $2^{\mathrm{b}}$ & 1468 & $6 \mathrm{~B}$ & 427 & 6.01 & 0.992 & 24 \\
\hline & TaAmy 1-B3 ${ }^{\mathrm{b}}$ & 1491 & $6 \mathrm{~B}$ & 425 & 5.84 & 0.989 & 22 \\
\hline & TaAmy1-B4 & 1494 & $6 \mathrm{~B}$ & 425 & 5.84 & 0.989 & 22 \\
\hline & TaAmy1-B5 & 1494 & $6 B$ & 425 & 5.84 & 0.989 & 22 \\
\hline & TaAmy1-B6 & 752 & $6 \mathrm{~B}$ & - & - & - & - \\
\hline & TaAmy1-D $1^{\mathrm{b}}$ & 1478 & $6 \mathrm{D}$ & 427 & 5.92 & 0.993 & 24 \\
\hline & TaAmy1-D2 ${ }^{\mathrm{b}}$ & 1476 & $6 \mathrm{D}$ & 425 & 6.10 & 0.990 & 24 \\
\hline & TaAmy1-D3 ${ }^{\mathrm{b}}$ & 1757 & $6 \mathrm{D}$ & 427 & 5.92 & 0.993 & 24 \\
\hline \multirow[t]{3}{*}{ Triticum urartu (PI428191) } & TuAmy1-A1 & 1479 & $6 \mathrm{~A}$ & 427 & 5.83 & 0.995 & 24 \\
\hline & TuAmy1-A2 & 1473 & $6 \mathrm{~A}$ & 427 & 6.00 & 0.995 & 24 \\
\hline & TuAmy1-A3 & 1774 & $6 \mathrm{~A}$ & 427 & 5.84 & 0.993 & 24 \\
\hline \multirow[t]{6}{*}{ Aegilops speltoides (PI542268) } & AesAmy1-B1 & 1475 & $6 B$ & 425 & 5.88 & 0.990 & 22 \\
\hline & AesAmy1-B2 & 1471 & $6 \mathrm{~B}$ & 425 & 5.92 & 0.990 & 22 \\
\hline & AesAmy1-B3 & 1478 & $6 \mathrm{~B}$ & 427 & 5.88 & 0.992 & 24 \\
\hline & AesAmy1-B4 & 1490 & $6 B$ & 427 & 5.81 & 0.993 & 24 \\
\hline & AesAmy1-B5 & 1510 & $6 \mathrm{~B}$ & 425 & 5.81 & 0.989 & 22 \\
\hline & AesAmy1-B6 & 1752 & $6 \mathrm{~B}$ & 427 & 5.92 & 0.993 & 24 \\
\hline \multirow[t]{3}{*}{ Aegilops tauschii (AS2404) } & AetAmy1-D1 & 1478 & $6 \mathrm{D}$ & 427 & 5.92 & 0.993 & 24 \\
\hline & AetAmy1-D2 & 1476 & $6 \mathrm{D}$ & 425 & 6.10 & 0.990 & 24 \\
\hline & AetAmy1-D3 & 1757 & $6 \mathrm{D}$ & 427 & 5.92 & 0.993 & 24 \\
\hline \multirow[t]{6}{*}{ Hordeum vulgare } & HvAmy1-1 & 1471 & $6 \mathrm{H}$ & 427 & 5.79 & 0.993 & 24 \\
\hline & HvAmy1-2 & 1471 & $6 \mathrm{H}$ & 427 & 5.79 & 0.993 & 24 \\
\hline & HvAmy1-3 & 1471 & $6 \mathrm{H}$ & 427 & 5.79 & 0.993 & 24 \\
\hline & HvAmy1-4 & 1485 & $6 \mathrm{H}$ & 427 & 5.74 & 0.994 & 24 \\
\hline & HvAmy $1-5$ & 1471 & - & 427 & 5.79 & 0.993 & 24 \\
\hline & HvAmy1-6c & 682 & $6 \mathrm{H}$ & - & - & - & - \\
\hline Brachypodium distachyon & BdAmy 1 & 1726 & 3 & 428 & 5.60 & 0.989 & 24 \\
\hline Brachypodium stacei & BsAmy 1 & 1650 & 4 & 428 & 5.46 & 0.991 & 24 \\
\hline \multirow[t]{2}{*}{ Oryza sativa } & OsAmy1-1 & 1567 & 2 & 428 & 5.07 & 0.994 & 25 \\
\hline & OsAmy1-2 & 1573 & 2 & 428 & 5.06 & 0.994 & 25 \\
\hline \multirow[t]{2}{*}{ Panicum hallii } & PhAmy1-1 & 1598 & 1 & 427 & 5.12 & 0.987 & 24 \\
\hline & PhAmy1-2 & 1590 & 1 & 427 & 4.98 & 0.986 & 23 \\
\hline Setaria italica & SiAmy1 & 1463 & 1 & 427 & 5.08 & 0.991 & 24 \\
\hline Setaria viridis & SVAmy 1 & 1463 & 1 & 427 & 5.08 & 0.991 & 24 \\
\hline \multirow[t]{2}{*}{ Sorghum bicolor } & SbAmy 1-1 & 1563 & 4 & 428 & 4.99 & 0.993 & 24 \\
\hline & SbAmy1-2 & 1860 & 4 & 428 & 6.16 & 0.995 & 24 \\
\hline Zea mays & ZmAmy 1 & 1651 & 5 & 428 & 5.18 & 0.986 & 24 \\
\hline
\end{tabular}

a Plant materials used for Amy1 isolation. ${ }^{\mathrm{b}}$ Eight cloned full-length Amy1 copies in CS. ${ }^{\mathrm{c}}$ The truncated copies from wheat and barley. ${ }^{\mathrm{d}} \mathrm{Chromosomes} .{ }^{\mathrm{e}} \mathrm{Secretory}$ pathway. ${ }^{\text {T}}$ The length of signal peptide 


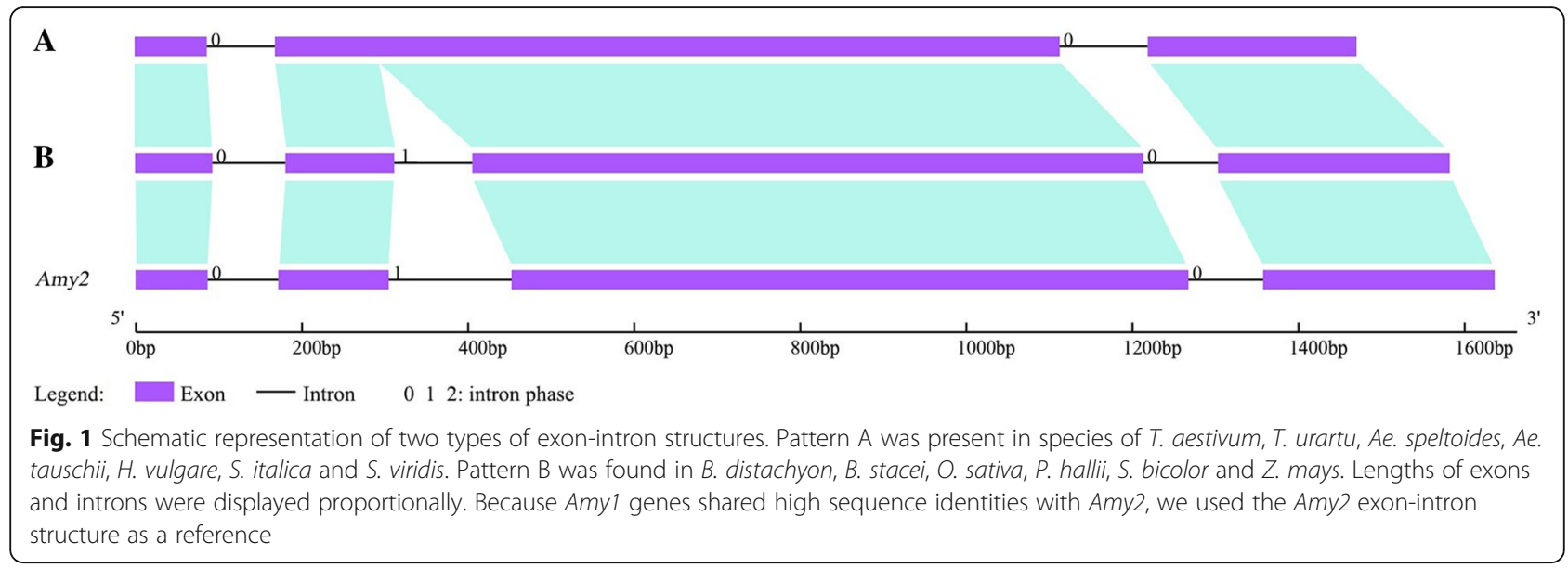

paralogs and orthologs were calculated as described previously [51]. Codon-based substitution models, M0 (one-ratio) and Two-ratios [52, 53], M1a (Neutral) and M2a (Selection) [54, 55], M3 (discrete), M7 (beta) and M8 (beta \& omega) [56], Model A and Model B [57, 58], were applied to detect branches or sites under positive selection, which were conducted using the codeml program [52] implemented in the PAML package [59]. Divergence time $(\mathrm{T})$ was obtained using a synonymous rate of $6.5 \times 10^{-9}$ substitutions per site per year [60-62] as $\mathrm{T}=\mathrm{Ks} /\left(2 \times 6.5 \times 10^{-9}\right)$.

\section{Synteny investigation and repeats annotation}

Chromosomes anchoring Amy1 loci were downloaded from online resources to construct a local genomic database. A total of 112 structural genes flanking the rice Amy1 locus (LOC_Os02g52700 and LOC_Os02g52710) were used as query markers to search against the local database using the basic tool NCBI-BLAST-2.4.0+ [63]. Reciprocal blastp [64] was carried out to confirm the orthologous relationships between pairs of corresponding structural markers. Genomic segments covering these markers were selected for detecting gene orders and synteny relationships. The identification of repetitive elements was analyzed by using a local BLASTN search against the non-redundant dataset of Triticeae Repeats (http://botserv2.uzh.ch/kelldata/trep-db/index.html).

\section{Protein structure homology modeling}

Two protein homologues, barley 1AMY [14] and rice 3WN6 [19], were extracted from the Protein Data Bank (PDB) archive (http://www.rcsb.org/pdb/home/home.do). Primary sequence alignment (not including the signal peptides) and secondary structure analysis were performed and displayed using the ESPript 3.0 server [65]. Annotation details of amino acids were inferred from the $\mathrm{Na}$ tional Center for Biotechnology Information (NCBI) conserved domain database [66]. Protein structure homology modeling was built in the workplace of SWISS-MODEL [67-69] based on the molecular structure of a barley $\alpha$-amylase-inhibitor complex (PDB ID: 1BG9) [70]. UCSF Chimera [71] was used for visualization and analysis of the resulting models.

\section{Alpha-amylase assay}

Developing grains were removed from the central part of the spikes. The wholemeal samples were dehydrated using VirTis freeze drying equipment and Lyophilizers (SP SCIENTIFIC). Alpha-amylase activity was determined following protocols of Whan et al. [22]. Data was expressed in ceralpha unit (CU) per g four or $\mu \mathrm{g}$ of protein as determined by Bradford assays [72] on the CERALPHA extracts.

\section{RNA extraction and qRT-PCR}

Total RNA from germinating seeds and developing grains was extracted using a TaKaRa RNAiso Plus kit (http://www.takara.com.cn/). RNA was quantified using NANODROP 2000c. Approximately $2 \mu \mathrm{g}$ of total RNA was used for reverse transcription and cDNA synthesis using TaKaRa Reverse Transcriptase M-MLV (RNase $\mathrm{H}-$ ) following the supplier recommendations. Real time PCR was performed using SYBR green PCR master mix (Bio-Rad) in a 20- $\mu \mathrm{L}$ reaction system on CFX Connect ${ }^{\mathrm{ma}}$ Real-Time PCR Detection System (Bio-Rad). RT-PCR data were extracted using CFX Manager 3.1 software (Bio-Rad) and analyzed by $2^{-\Delta C T}$ method. The expression of TaActin [22, 73] was used as an internal control for normalization. All the primers used in this work were listed in Additional file 1.

\section{Results}

\section{Identification of Amy1 genes in grass}

As summarized in Table 1, a total of 41 Amy1 genes were identified from the 13 investigated grass species. In bread wheat, there are three full-length copies in each of 
$\mathrm{A}$ and $\mathrm{D}$ genomes, and six copies (five full-length and one truncated TaAmy1-B6) in B genome. We also isolated these A- and D-genome copies in T. aestivum, $T$. urartu and Ae. tauschii, respectively. Multiple sequence alignment indicated that the genomic sequences of $\mathrm{TaA}$ my1-D1, TaAmy1-D2 and TaAmy1-D3 were identical to AetAmy1-D1, AetAmy1-D2 and AetAmy1-D3, respectively. Pairwise identities were $98.7 \%$ between TaAmy1-A1 and TuAmy1-A1, 99.7\% between TaAmy1-A2 and TuAmy1-A2, and $99.1 \%$ between TaAmy1-A3 and TuAmy1-A3. As for the B genome, we cloned three full-length copies (TaAmy1-B1, TaAmy1-B2 and TaAmy1-B3) in T. aestivum and six (AesAmy1-B1 to AesAmy1-B6) in Ae. speltoides, and pairwise identities (88.1 to $97.8 \%$ ) were significantly lower than that of A and D genomes. All the isolated $A m y 1$ sequences are clustered in Additional file 2. The existence of TaAmy1-B6 was verified by using primer pair TaAmy1-B6-F/R (Additional file 3A).

In barley, we identified five copies located on the chromosome $6 \mathrm{H}$, and three copies with unknown chromosomal locations. Because of existence of gapped sequences in the coding region, two of them were discarded for further analyses. Similar to TaAmy1-B6, HvAmy1-6 was also a truncated copy with approximate $682 \mathrm{bp}$ gene sequences retained. Additionally, in silico analysis indicated that two copies were found in each of O. sativa, P. hallii and S. bicolor. Only a single copy was identified in each of B. distachyon, B. stacei, S. italica, S. viridis and $Z$. mays.

Exon and intron analysis revealed two types of exon-intron structures (Fig. 1). Pattern A contained three exons and two introns, whereas the second exon of pattern B was interrupted by a middle intron and separated into two exons. Furthermore, we calculated theoretical pI values, which range from 4.98 to 6.10 . All the full-length Amy1 genes showed strong signals in secretory pathway $(\mathrm{SP} \geq 0.986)$, and the length of signal peptides varied from 22 to 25 amino acids.

\section{Phylogenetic and syntenic relationships}

To determine evolutionary relationship of Amy1 family in grass, the phylogeny was reconstructed based on the maximum-likelihood method. The phylogenetic tree segregated Amy1 genes into three major clades with high bootstrap supports (99\% or $100 \%)$, corresponding to the three subfamilies (Pooideae, Ehrhartoideae and Panicoideae) in grass (Fig. 2). In the Pooideae-Triticeae clade, 28 identified sequences from five Triticeae species were clustered into two groups: Group 1 (G1) and Group 2 (G2). G1 contained 14 members: two in each of T. urartu, Ae. tauschii, genomes A, B and D of wheat, three in Ae. speltoides, and one in $H$. vulgare. G2 contained one in each of T. urartu, Ae. tauschii, genomes A and D of wheat, three in each of

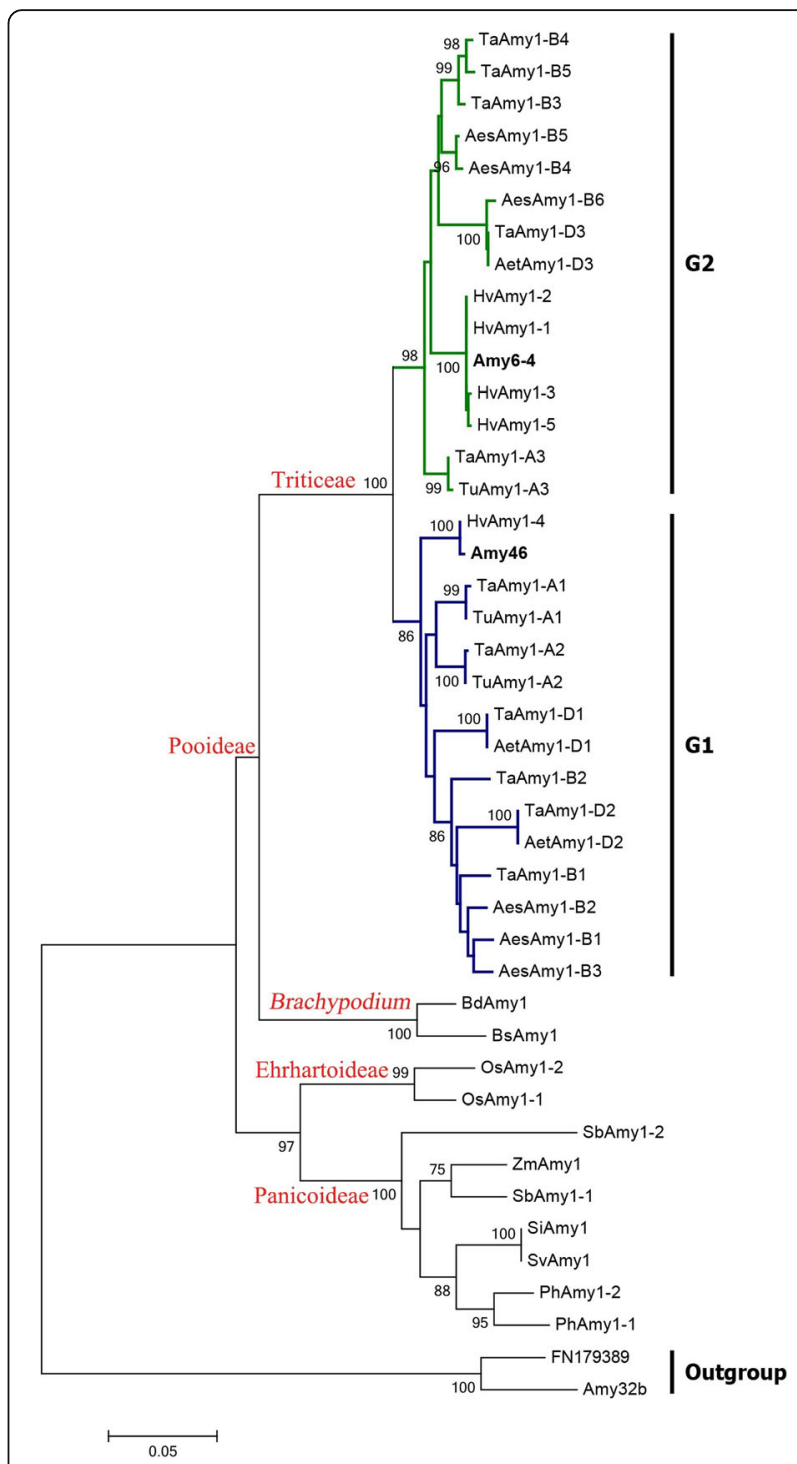

Fig. 2 Phylogenetic analysis of grass Amy1 genes. Forty-three protein-coding sequences from 13 species were involved. The tree is rooted on midpoint and drawn to scale, with branch lengths measured in the number of substitutions per site. A discrete Gamma distribution was used to model evolutionary rate differences among sites $[5$ categories $(+G$, parameter $=0.4987)]$. Two low-pl Amy2 genes, FN179389 [23] and Amy32b (GenBank accession no. X05166) were used as outgroup

Ae. speltoides and B genome, and four in $H$. vulgare. We further estimated the evolutionary distances. All the three clades (Pooideae-Brachypodium, Ehrhartoideae and Panicoideae) exhibited larger genetic distances with G1 than those with G2 (Additional file 4), suggesting that G2 might be the ancient archetype Amy1 genes in Triticeae.

To make insights into structural organization of Amy1 loci, the linear gene orders were analyzed across six grass genomes (Fig. 3A). The Amy1 regions in wheat and barley shared highly conserved gene orders. 


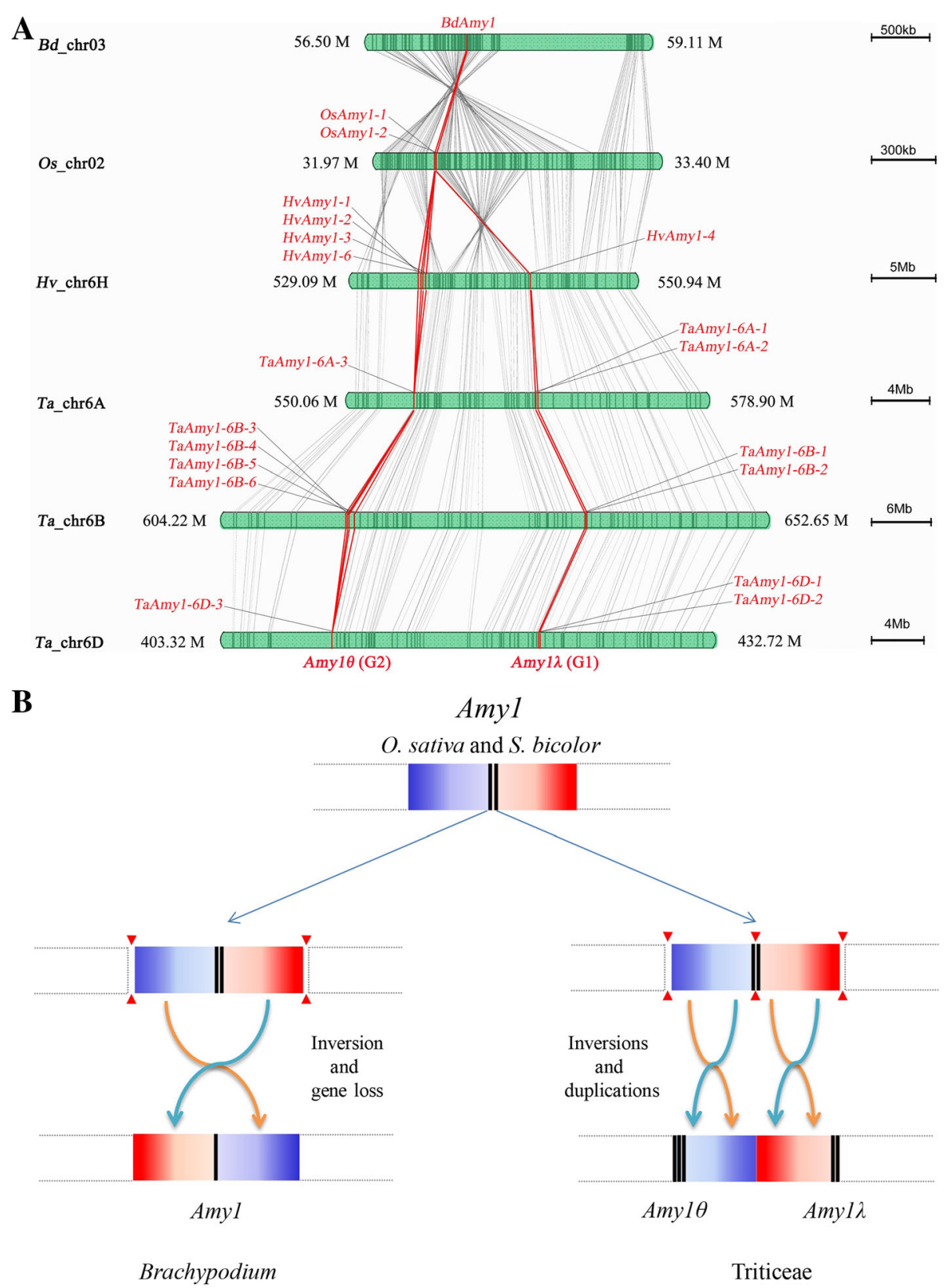

Fig. 3 (a) Synteny relationships of genomic segments covering Amy 1 loci in rice, wheat, barley and B. distachyon. The Amy 1 genes were red highlighted and scale bars were proportional to the length of chromosomal segments. (b) Schematic illustration of structural variations of Amy1 region

However, compared to Amy1 genes of rice located in the middle of segments, those of wheat and barley were dispersed on both ends of corresponding segments. The segments seemed to be separated into two parts, each of them was involved in an inversion event. A tandem gene duplication event was also found, which resulted in expansion of Amy1 family (Fig. 3A, B). The two Amy1 gene clusters apart from each other were corresponding to the phylogenetic groups $\mathrm{G} 1$ and G2, temporarily des-

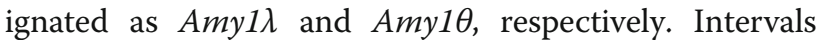

between them, ranging from approximately $8.36 \mathrm{Mb}$ on chromosome $6 \mathrm{H}$ to $21.42 \mathrm{Mb}$ on chromosome $6 \mathrm{~B}$, were rich in repetitive elements such as long terminal repeat (LTR) retrotransposons and DNA transposons (Fig. 3A, Additional file 5).

\section{Divergence time of Amy $1 \lambda$ from Amy $1 \theta$}

As mentioned above, a tandem gene duplication event, followed by chromosomal rearrangements, led to the fix-

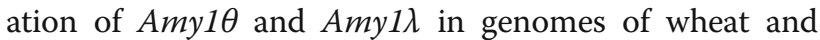


barley. Considering a single Amy1 copy in genera Brachypodium, this structural variation might occur prior to the divergence of wheat from barley (11.6 MYA) and after the divergence of wheat from Brachypodium (32-39 MYA) [42, 74]. To verify it, we calculated the pairwise mean synonymous substitution rates (dS) and estimated when this duplication event occurred. The di-

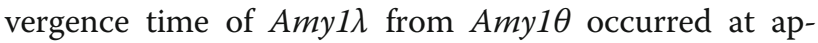
proximately $36.3 \pm 6.2$ MYA in A genome $(31.6 \pm 5.7$ MYA in T. urartu), $31.2 \pm 5.6$ MYA in B genome (39.4 \pm 6.9 MYA in Ae. speltoides), 42.9 \pm 7.7 MYA in D genome (42.9 \pm 7.7 MYA in Ae. tauschii), and $36.0 \pm 6.6$ MYA in barley (Table 2). These results agreed with our hypothesis, and our estimates also suggested a higher substitution rate of $A m y 1$ genes than the average $6.5 \times 10^{-9}$ in grass nuclear genes.

\section{Potential natural selection on Amy $1 \lambda$ genes}

We applied nine different codon-substitution models to detect selection pressures at individual sites along specific lineages. Results obtained were presented in Table 3.
The one-ratio model (M0) produced an estimated $\omega_{0}=0.0519$. The two-ratio model assigned two different $\omega$ ratios for the foreground branch G1 $\left(\omega_{1}=0.182\right)$ and for all other background branches $\left(\omega_{0}=0.0513\right)$. Sitespecific models indicated variable selective pressures among these 424 codons. For example, the M3 model $(\mathrm{K}=2)$ fit the data better than the one-ratio model, the Likelihood Ratio Test (LRT) statistics were $2 \Delta \ell=420$, with $P<0.001$ and $\mathrm{df}=2$. Both the branch models and site-specific models failed to detect sites under positive selection, and most sites appeared to be under strong purifying selection. The branch-site model A fit the data significantly better than M1a, the test statistics were $2 \Delta \ell=3.6$, with $P=0.06$ and $\mathrm{df}=1$. Model $\mathrm{B}$ did not fit the data significantly better than M3 (discrete with $\mathrm{K}=2)(2 \Delta \ell=3.68, P=0.16, \mathrm{df}=2)$, but it suggested a proportion of sites $(19.7 \%)$ were under positive selection along the G1 branch with $\omega_{2}=1.197$. Both in Model A and Model B, four sites (56 V, 119R, $189 \mathrm{~K}, 254 \mathrm{~N}$ ) have been detected under selection at a less significant level $\left(0.50<P<0.95^{*}\right)$ in the Bayes Empirical Bayes analysis

Table 2 Estimation of duplication and divergence time between groups

\begin{tabular}{|c|c|c|c|}
\hline Pairwise comparison & $\mathrm{dS}^{\mathrm{a}}$ & Average $\mathrm{dS}^{\mathrm{a}}$ & $T\left(M Y A^{b}\right)$ \\
\hline TaAmy1-A3 vs TaAmy1-A1 & $0.5080 \pm 0.0869$ & $0.4725 \pm 0.08095$ & $36.3 \pm 6.2$ \\
\hline TaAmy1-A3 vs TaAmy1-A2 & $0.4370 \pm 0.0750$ & & \\
\hline TuAmy1-A3 vs TuAmy1-A1 & $0.4143 \pm 0.0745$ & $0.4113 \pm 0.07355$ & $31.6 \pm 5.7$ \\
\hline TuAmy1-A3 vs TuAmy1-A2 & $0.4082 \pm 0.0726$ & & \\
\hline TaAmy1-B4 vs TaAmy1-B1 & $0.3397 \pm 0.0620$ & $0.4062 \pm 0.07242$ & $31.2 \pm 5.6$ \\
\hline TaAmy1-B4 vs TaAmy1-B2 & $0.3996 \pm 0.0699$ & & \\
\hline TaAmy1-B5 vs TaAmy1-B1 & $0.3568 \pm 0.0641$ & & \\
\hline TaAmy1-B5 vs TaAmy1-B2 & $0.4244 \pm 0.0730$ & & \\
\hline TaAmy1-B3 vs TaAmy1-B1 & $0.4334 \pm 0.0805$ & & \\
\hline TaAmy1-B3 vs TaAmy1-B2 & $0.4822 \pm 0.0850$ & & \\
\hline AesAmy1-B4 vs AesAmy1-B1 & $0.5588 \pm 0.0946$ & $0.5129 \pm 0.09034$ & $39.4 \pm 6.9$ \\
\hline AesAmy1-B4 vs AesAmy1-B2 & $0.4935 \pm 0.0871$ & & \\
\hline AesAmy1-B4 vs AesAmy1-B3 & $0.4638 \pm 0.0834$ & & \\
\hline AesAmy1-B5 vs AesAmy1-B1 & $0.5355 \pm 0.0901$ & & \\
\hline AesAmy1-B5 vs AesAmy1-B2 & $0.4568 \pm 0.0801$ & & \\
\hline AesAmy1-B5 vs AesAmy1-B3 & $0.4763 \pm 0.0863$ & & \\
\hline AesAmy1-B6 vs AesAmy1-B1 & $0.6168 \pm 0.1090$ & & \\
\hline AesAmy1-B6 vs AesAmy1-B2 & $0.4839 \pm 0.0836$ & & \\
\hline AesAmy 1-B6 vs AesAmy 1-B3 & $0.5311 \pm 0.0989$ & & \\
\hline TaAmy1-D3 vs TaAmy1-D1 & $0.6974 \pm 0.1287$ & $0.5584 \pm 0.1003$ & $42.9 \pm 7.7$ \\
\hline TaAmy1-D3 vs TaAmy1-D2 & $0.4193 \pm 0.0719$ & & \\
\hline AetAmy1-D3 vs AetAmy1-D1 & $0.6974 \pm 0.1287$ & $0.5584 \pm 0.1000$ & $42.9 \pm 7.7$ \\
\hline AetAmy1-D3 vs AetAmy1-D2 & $0.4193 \pm 0.0719$ & & \\
\hline HvAmy 1-4 vs HvAmy1-1 & $0.4682 \pm 0.0858$ & $0.4684 \pm 0.0858$ & $36.0 \pm 6.6$ \\
\hline HvAmy1-4 vs HvAmy1-2 & $0.4682 \pm 0.0858$ & & \\
\hline HvAmy1-4 vs HvAmy1-3 & $0.4687 \pm 0.0859$ & & \\
\hline HvAmy $1-4$ vs HvAmy $1-5$ & $0.4687 \pm 0.0859$ & & \\
\hline
\end{tabular}

${ }^{\mathrm{a}}$ Number of substitutions per synonymous site. ${ }^{\mathrm{b}}$ Million years ago 
Table 3 Analysis of potential natural selection analysis among Amy1 genes

\begin{tabular}{|c|c|c|c|c|}
\hline Model & $p^{a}$ & $e^{b}$ & Estimates of Parameters & Positive Selected Sites \\
\hline M0: one-ratio & 1 & -7710.25 & $\omega_{0}=0.0519$ & $N A^{c}$ \\
\hline \multicolumn{5}{|l|}{ Branch model } \\
\hline Two-ratios & 2 & -7708.92 & $\omega_{0}=0.0513, \omega_{1}=0.182$ & None \\
\hline \multicolumn{5}{|l|}{ Site-specific model } \\
\hline \multirow[t]{2}{*}{ M1a: neutral } & 2 & -7606.65 & $p_{0}=0.938\left(p_{1}=0.0620\right)$ & $N A^{c}$ \\
\hline & & & $\omega_{0}=0.0409\left(\omega_{1}=1.000\right)$ & \\
\hline \multirow[t]{2}{*}{ M2a:selection } & 4 & -7606.65 & $p_{0}=0.938, p_{1}=0.0620\left(p_{2}=0.000\right)$ & $3975(P=0.57)$ \\
\hline & & & $\begin{array}{l}\omega_{0}=0.0409\left(\omega_{1}=1.000\right) \\
\omega_{2}=1.000\end{array}$ & \\
\hline \multirow[t]{2}{*}{ M3: discrete $(K=2)$} & 3 & -7500.24 & $p_{0}=0.776\left(p_{1}=0.224\right)$ & None \\
\hline & & & $\omega_{0}=0.0131, \omega_{1}=0.219$ & \\
\hline \multirow[t]{2}{*}{ M3: discrete $(K=3)$} & 5 & -7487.11 & $p_{0}=0.705, p_{1}=0.240\left(p_{2}=0.0549\right)$ & None \\
\hline & & & $\omega_{0}=0.009, \omega_{1}=0.131, \omega_{2}=0.446$ & \\
\hline M7: beta & 2 & -7490.53 & $p=0.254 q=3.432$ & $N A^{c}$ \\
\hline \multirow[t]{2}{*}{ M8: beta\& $\omega>1$} & 4 & -7488.21 & $p_{0}=0.989\left(p_{1}=0.0108\right)$ & None \\
\hline & & & $p=0.281, q=4.425, \omega_{s}=1.000$ & \\
\hline \multicolumn{5}{|l|}{ Branch-site model } \\
\hline \multirow[t]{3}{*}{ Model A } & 3 & -7604.85 & $p_{0}=0.878, p_{1}=0.0484$ & Foreground lineage $\omega_{2}\left(B \in B^{d}\right)$ : \\
\hline & & & $\left(p_{2 a}+p_{2 b}=0.0736\right)$ & $56 \mathrm{~V} 119 \mathrm{H} 189 \mathrm{~K} 254 \mathrm{D}$ \\
\hline & & & $\omega_{2}=1.000$ & $(0.70<P<0.95)$ \\
\hline \multirow[t]{5}{*}{ Model B } & 5 & -7498.40 & $p_{0}=0.620$ & Foreground lineage $\omega_{2}\left(N E B^{d}\right)$ : \\
\hline & & & $p_{1}=0.183\left(p_{2 a}+p_{2 b}=0.197\right)$ & $119 \mathrm{H} 254 \mathrm{D}\left(P>0.95^{*}\right)$ \\
\hline & & & $\omega_{0}=0.0125, \omega_{1}=0.216$ & Foreground lineage $\omega_{2}\left(B \in B^{d}\right)$ : \\
\hline & & & $\omega_{2}=1.197$ & $56 \mathrm{~V} 119 \mathrm{H} 189 \mathrm{~K} 254 \mathrm{D}$ \\
\hline & & & & $(0.50<P<0.85)$ \\
\hline
\end{tabular}

${ }^{\mathrm{a}}$ The number of free parameters for $\omega$ distribution. ${ }^{\mathrm{b}}$ Value of log likelihoods. ${ }^{\mathrm{c}}$ Not allowed. ${ }^{\mathrm{d}}$ NEB Naive Empirical Bayes, BEB Bayes Empirical Bayes. Amino acids refer to the first sequence: BdAmy1

(BEB), and sites 119R (His97Arg) and $254 \mathrm{~N}$ (Asp233Asn) were up to the significant level $\left(P>0.95^{*}\right)$ in the Naive Empirical Bayes analysis (NEB).

\section{Homology modeling}

To check if there exists some functional divergence between proteins of Amy $1 \theta$ and Amy $1 \lambda$, initially, we analyzed the primary and secondary structures. We found two group-specific amino acid substitutions, His97Arg and Asp233Asn, located on the 4th $\beta$-strand in domain B and the 6th $\alpha$-helix in domain A, respectively (Fig. 4). Then we built protein models, and found that when $\mathrm{Asp}_{233}$ was replaced by $A_{2 s}{ }_{233}$, Amy1 $\lambda$ proteins failed to form the $\alpha$-amylase-acarbose inhibitor complex (Amy1-AF1) in the SBS1 region (Additional file 6).

\section{Expression profiles of Amy 1 genes}

We quantified transcript levels of $A m y 1 \theta$ and $A m y 1 \lambda$ genes at germinating or early seedling stages. In bread wheat (cv. $\mathrm{CS})$, the 11 full-length copies were divided into five subgroups, TaAmy1-A1/A2, TaAmy1-D1, TaAmy1-B1/B2/D2, TaAmy1-A3/D3 and TaAmy1-B3/B4/B5, based on sequence homology. TaAmy1-B1/B2/D2 transcripts were the most abundant, followed by TaAmy1-D1 and TaAmy1-A3/ D3, and subgroups TaAmy1-A1/A2 and TaAmy1-B3/B4/B5 were less expressed under all the four sampling points (Fig. 5A). In barley (cv. Morex), HvAmy1 $\theta$ was significantly expressed at higher levels than $H v A m y 1 \lambda$ (Fig. 5B).

We introduced three wheat lines with high levels of $\alpha$-amylase activities in ripe grains and three extreme low-level landraces for $\alpha$-amylase assay (Additional file 7). In the grain development, all the six lines retained high $\alpha$-amylase activities until $24 \mathrm{DPA}$; and from $26 \mathrm{DPA}$ through to the end, high-level lines declined with lower rates and resulted in higher levels compared with the landraces (Fig. 6A). These changes prompted us to further investigate whether the Amy1 copies were differentially expressed among these lines. Using an universal primer pair TaAmy1-RT-F/R, we observed an overall expression peak in Guinong19 at 28 DPA, which appeared slightly later in Mianmai43 and Jinan17. Their transcript levels were significantly higher than those of the other three landraces at 30 DPA (Fig. 6B). Further we performed copy-specific analysis at 28 DPA. It showed that the overall expression of TaAmy1 in developing grains was largely contributed by TaAmy1-A1/A2 and 

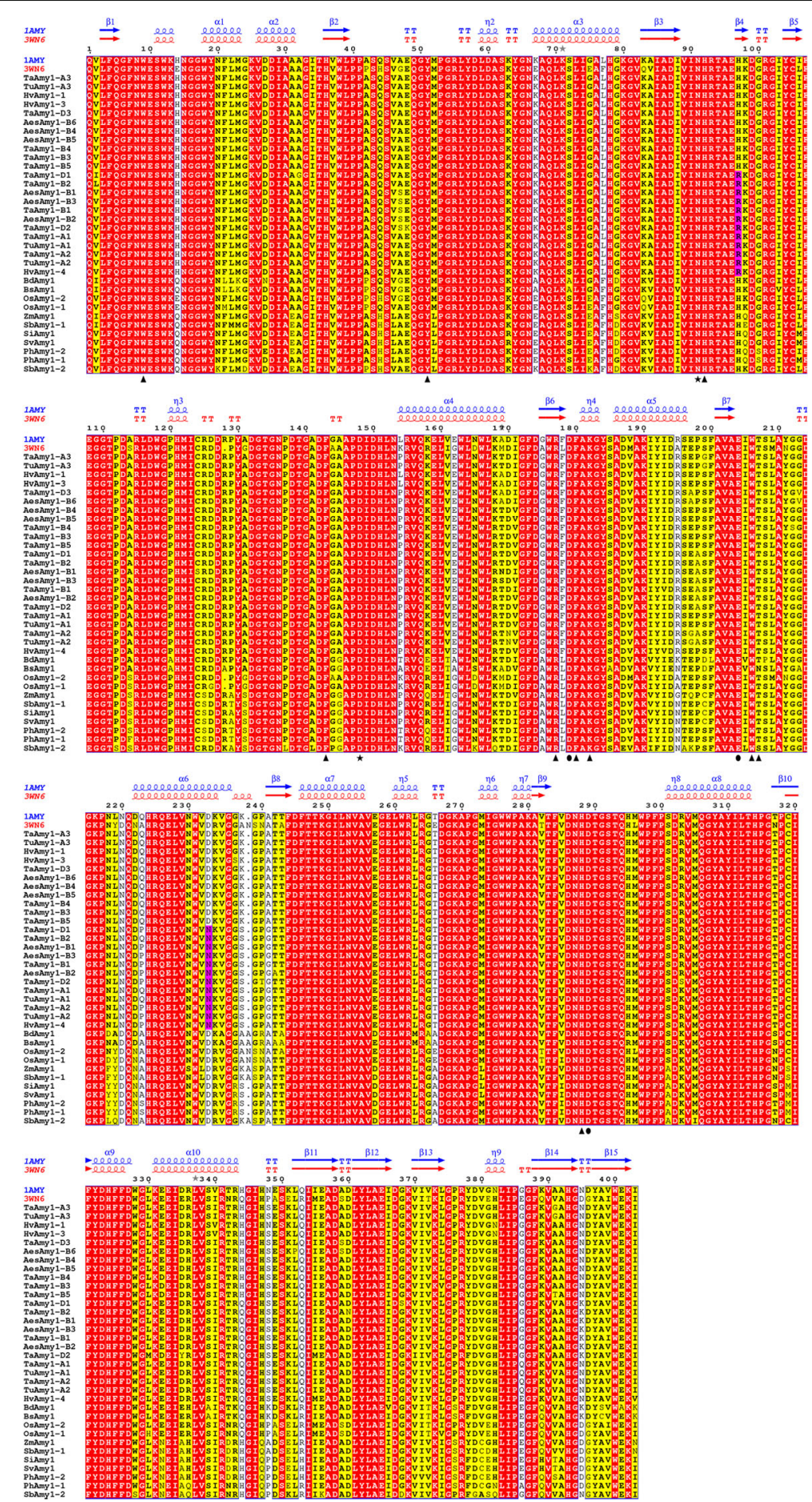

Fig. 4 Protein sequence alignment of 403 amino acid residues. Secondary structure prediction was based on structures of barley 1 AMY (blue) and rice 3 WN6 (red) with a-helices displayed as coils, $\beta$-strands as arrows, strict $\beta$-turns as $\Pi$ letters, active sites as triangles, $\mathrm{Ca}^{2+}$ binding sites as stars and catalytic sites as circles. Domain A: a $(\beta / a)_{8}$-barrel of 286 residues, domain B: 64 residues, connecting strand $\beta_{3}$ and helix $a_{4}$ of the barrel, domain C: 53 residues forming a five stranded anti-parallel $\beta$-sheet. Two amino acids ( $\operatorname{Arg}_{97}$ and $\mathrm{Asn}_{233}$ ), specific to $A m y 1 \lambda$ proteins, were highlighted in pink 

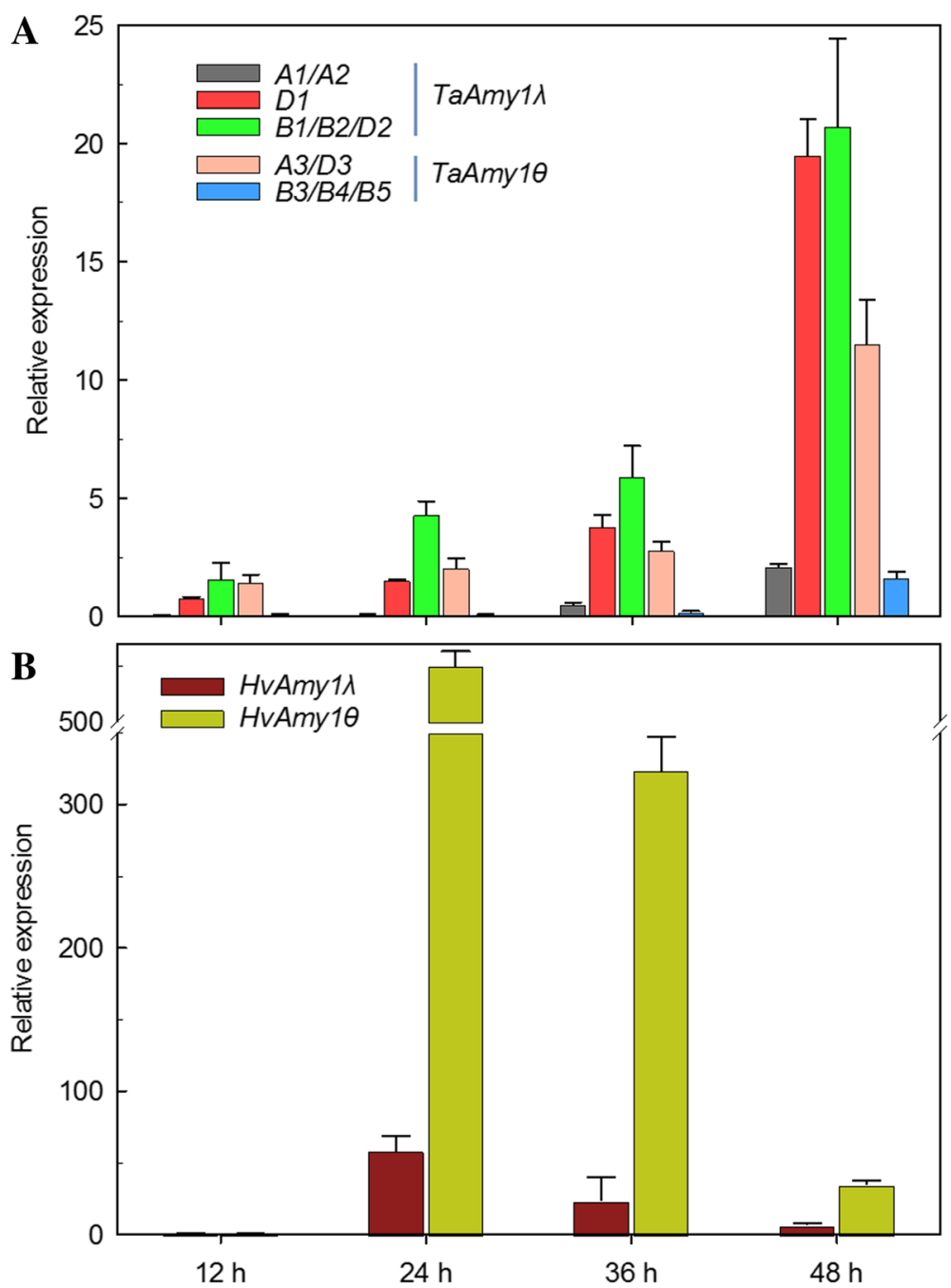

Fig. 5 The relative expression levels of Amyl genes in wheat (cv. CS, A) and barley (cv. Morex, B) during germinating or early seedling stages. Three technical replicates were performed in each expression analysis. Error bars represent SE

TaAmy1-D1, while TaAmy1-B1/B2/D2, TaAmy1-A3/D3 and TaAmy1-B3/B4/B5) were hardly detected (Fig. 6C).

\section{Discussion}

\section{Copy number variation of Amy1 genes in bread wheat} and barley

In this work, by molecular cloning and in silico analysis employing genomic resources generated recently, we isolated Amy1 genes in bread wheat and its diploid progenitors, T. urartu, Ae. speltoides and Ae. tauschii, representing the $\mathrm{A}, \mathrm{B}$ and $\mathrm{D}$ genomes, respectively (Table 1), although the real progenitor of $B$ genome has been in debate for years [75, 76]. Compared with their corresponding counterparts of bread wheat, the Amy1 genes of T. urartu and Ae. tauschii are highly conserved in terms of copy number and sequence identity, while those of Ae. speltoides are rather variable, which is consistent with previous reports [4]. Probably due to the amplification bias, we failed to experimentally isolate copies TaAmy1-A3, TaAmy1-B4 and TaAmy1-B5 (Table 1, Additional file 2) from CS, which could be retrieved from its whole genome sequence. However, we have confirmed their presence and the extremely high inter-cultivar conservation of each copy through sequencing more than 220 clones from 17 wheat lines.

In barley, eight Amy1 copies were detected, which was consistent with the results recently presented by Mascher et al. [77]. However, some nomenclature confusion has arisen as genes for high-pI isoforms have been alternatively called Amy1 [26] and Amy2 [78] for many years. Radchuk et al. [23] submitted a barley $\alpha$-amylase sequence named as $H v A M Y 3$ (GenBank accession no. FN179391), which had an identity of $99 \%$ with Amy6-4 and 95\% with Amy46. Actually, it should not represent a new gene family [22], but belongs to the Amy1 

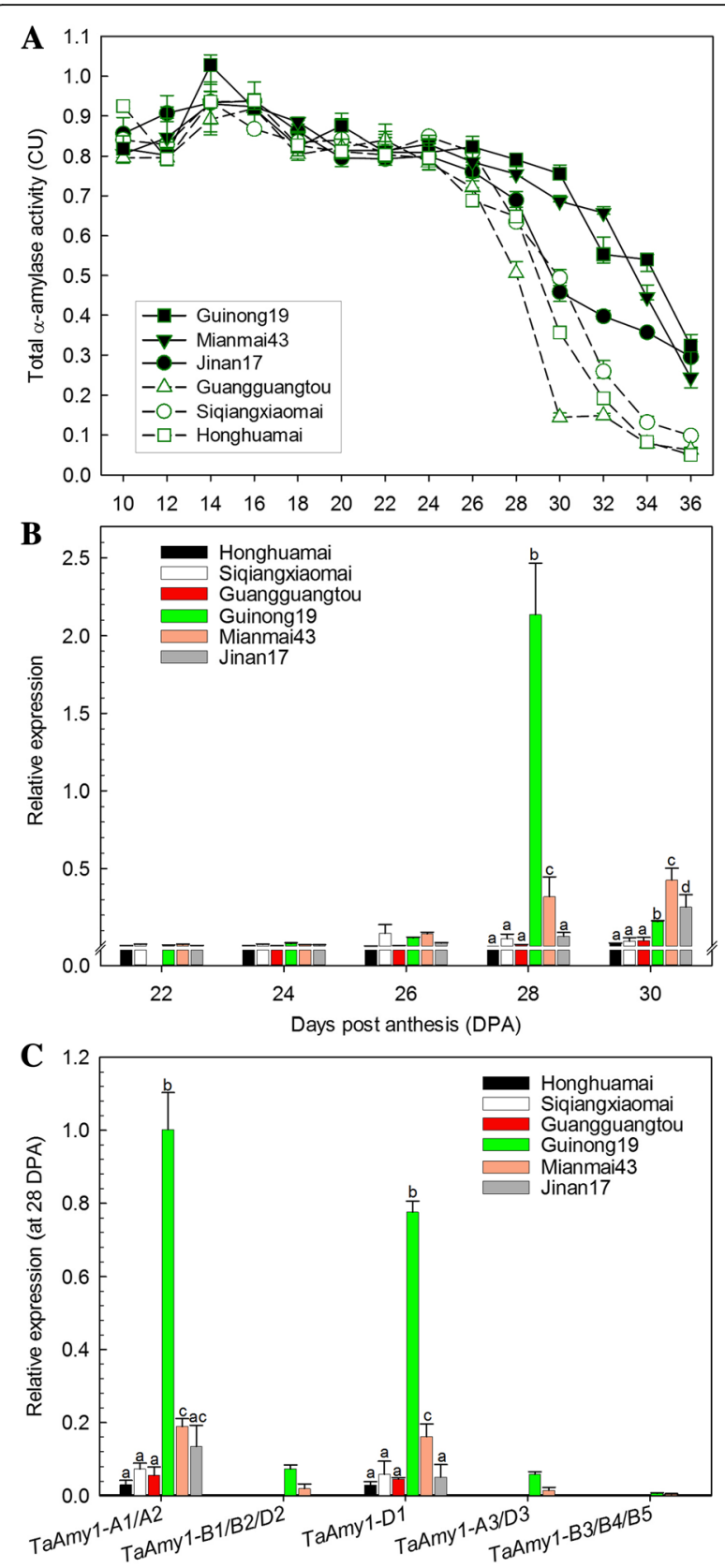

Fig. 6 Dynamic changes of total a-amylase activities and expression levels of TaAmy1 genes during grain development. (a) Changes of total a-amylase activities. (b) TaAmy 1 relative expression during late stages of grain development. (c) Relative expression of five TaAmy 1 subgroups at 28 DPA. Three technical replicates were performed in each expression analysis. Significance values were calculated using Duncan's multiple range tests. Error bars represent SE

multigene family. Interestingly, in genomes of wheat and barley, we have found two interrupted Amy1 fragments: TaAmy1-B6 and HvAmy1-6, respectively. Analysis of their $4.1 \mathrm{~kb}$ upstream sequence indicates this truncating event might be caused by the insertion of a $1.2 \mathrm{~kb}$ Gypsy retrotransposon (Additional file 3B).

\section{Structural variation of Amy 1 loci in Pooideae}

Syntenic analysis of Amy1 loci revealed apparent structural variations between Pooideae and the other grass species analyzed in this study. Despite of the conserved linear gene order extensively reported in previous genome wide analyses [42, 79, 80], we found a segmental inversion around the Amy1 loci occurring between $56.50 \mathrm{Mb}-59.11 \mathrm{Mb}$ on chromosome 3 of $B$. distachyon comparing to corresponding region on chromosome 2 of rice (from $31.97 \mathrm{Mb}$ to 33.40 $\mathrm{Mb})$ (Fig. 3A). In corresponding regions on chromosomes 6 of barley and wheat, at least two segmental inversion events were observed (Fig. 3A, B). These structural alterations split the original Amy1 locus into two separated loci: $A m y 1 \theta$ and $A m y 1 \lambda$, which resulted in significantly altered organization of $A m y 1$ comparing to those of some other grass species. The existence of these two Amy1 loci was supported by the results of Nishikawa et al. [81] and Cheung et al. [82], who described two separated TaAmy1 loci and five TaAmy1 copies dispersed on chromosome 6B. Three individual Rye $A m y 1$ genes also provided some evidence of recombination and spanned a distance of $3 \mathrm{cM}$ at the locus on chromosome 6RL [29]. The repeats invasion, especially LTR retrotransposon Copia (RLC) and Gypsy (RLG), and DNA transposon CACTA superfamily (DTC), also contributed to extension of intervals between $A m y 1 \theta$ and $A m y 1 \lambda$ (Additional file 5).

Gene duplication is critical in supplying raw genetic materials to form gene families and producing new functions [83]. Copy number variation also reflects the dynamic genome evolutionary patterns. In wheat and barley, we have observed apparent evidence of tandem gene duplications, for example, four paralo-

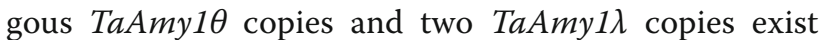
in chromosome 6B (Fig. 3A). These inter-group duplication events might occur prior to the intra-group duplications, as suggested by divergence time estimates (Table 2, Additional file 8). These results indicated that the Pooideae species underwent complex genome evolution.

Chromosomal distribution indicates that Amy1 loci are located on the conserved block 5 (ancestral chromosome A4), which only experiences a whole genome duplication (WGD), followed by chromosomal breakage and shuffling before divergence of these three subfamilies (Pooideae, Ehrhartoideae and Panicoideae) in grass $[41,42,79]$. On the knowledge of grass establishment and $A m y 1$ structural variation, we proposed an evolutionary model of $A m y 1$ genes. As illustrated in Fig. 7, the original single-copy structural locus in grass (Amy1) retains in species of $B$. distachyon, $B$. stacei, $S$. italica, $S$. viridis and $Z$. mays, respectively. 


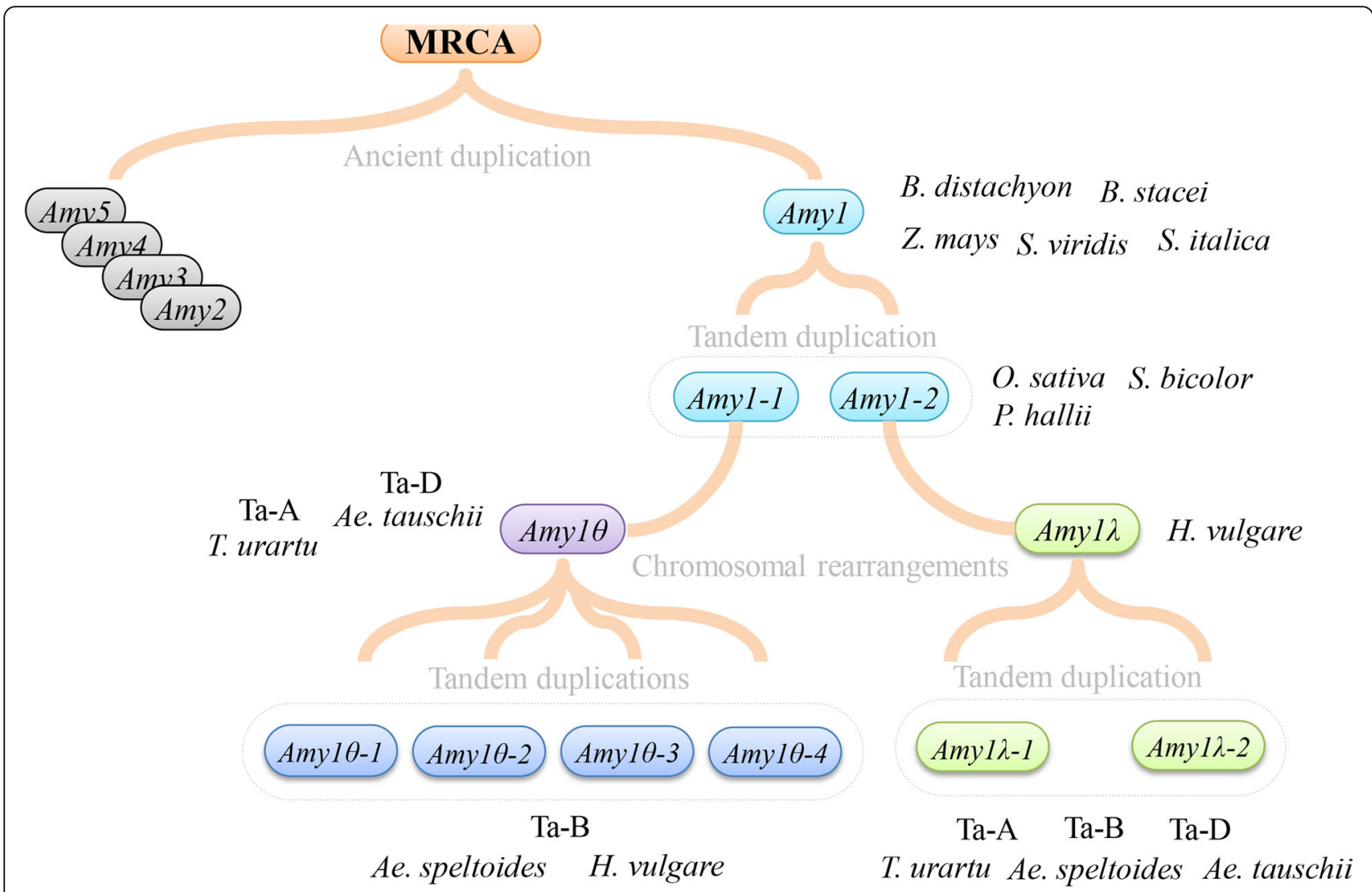

Fig. 7 A proposed evolutionary model for Amy 1 locus from the most recent common ancestor (MRCA) among grass

Two-copy species of O. sativa, S. bicolor and P. hallii, each experiences a tandem gene duplication event. In Triticeae species, Amy1 is firstly duplicated into a pair of intermediate tandem repeats (Amy1-1 and Amy1-2). Ever since this duplication, followed by chromosomal rearrangement, Amy1-2 has evolved and diverged from Amy1-1 under limited adaptive selections (Table 3). Two distinct loci, Amy10 (Amy1-1) and Amy1d (Amy1-2), have been eventually fixed in genomes. Subsequently, several rounds of other recent tandem duplications within each locus continue to enlarge this multigene family. Nevertheless, Amy1 genes are absent in Dicot lineage, and should emerge after the branch of Dicots-Monocots, indicating the origin of the most recent common ancestor (MRCA) must have resulted from gene duplication.

\section{Divergence between Amy $1 \lambda$ and Amy $1 \theta$ genes and functional importance}

Not only the separation on physical positions, sequences

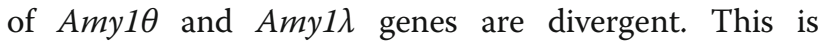
reflected by the phylogenetic analysis for that the $A m y 1 \theta$ and $A m y 1 \lambda$ genes were clustered distinctly into two groups (Fig. 2), corresponding to groups G2 and G1, respectively. Additionally, length of the first intron varies

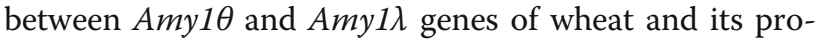
genitors. For example, the lengths of $370 \mathrm{bp}$ or $380 \mathrm{bp}$ were specifically appeared in $A m y 1 \theta$, while this variation

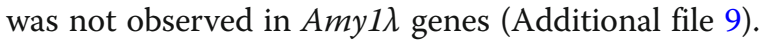

The fates (nonfunctionalization, neofunctionalization or subfunctionalization) of duplicated genes were strongly directed by adaptive selection [61, 84]. The nonsynonymous to synonymous substitution rate ratio $(\omega=\mathrm{dN} / \mathrm{dS})$ is clearly recognized as a sensitive measure of positive selection at the nucleotide or protein levels. Using nine different codon-substitution models, we have identified two codon sites $\left(\mathrm{Arg}_{97}\right.$ and $\left.\mathrm{Asn}_{233}\right)$ in $A m y 1 \lambda$ genes under selection pressures (Table 3 ). The substitution of His97Arg was located on the 4th $\beta$-strand in domain B (Fig. 4), and did not share any functional evidence according to previous studies. The other codon site, Asp233Asn, was situated at the surface binding site (SBS1). SBS1 was involved in starch binding and substrate recognition $[15,20,85]$. This binding site owned two consecutive tryptophan residues (Additional file 6), which were characteristic of and functionally essential for cereal Amy1 or Amy2 isoforms $[14,15,70]$. Mutations on them strongly affected the 
ability of SBS1 binding to different starch types [85]. However, roles of these other surrounding residues (Asp233Asn, Gln226 and Val229 in Additional file 6) in starch binding or degradation have not yet been reported. Therefore, whether this substitution is functionally vital or not remains undiscovered. As the archetype Amy10 genes commonly existing among grasses, the appearance of derivative Amy $1 \lambda$ genes indicates an unique gene duplication event in Triticeae species, and possibly implicated the potential subfunctionalization of Amy1 after divergence of the two groups.

Patterns of gene expression are usually associated with functional differentiation. In the present work, all the five subgroups of TaAmy1 and two subgroups of HvAmy1 are active in transcription during seed germination (Fig. 5A, B), indicating that the seed germination is triggered by the coordinated expressions of multiple $A m y 1 \theta$ and $A m y 1 \lambda$ genes. In barley, $H v A m y 1 \theta$ (at least four copies) exhibited significantly higher abundance than that of $H v A m y 1 \lambda$ (one copy) during germination (Fig. 5B). Considering great difference on copy number, the differential expression levels most likely owe to dosage effect. In wheat, both during germination and in the developmental stages, our study indicated that TaAmy $1 \lambda$ and TaAmy1O genes were differentially

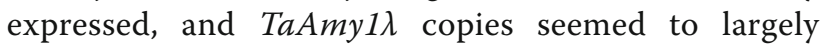
contribute to the total abundance of TaAmy1 genes. For example, TaAmy1-D1 and TaAmy1-B1/B2/D2 during germination, and TaAmy1-A1/A2 and TaA$m y 1-D 1$ in the developing grains were the main

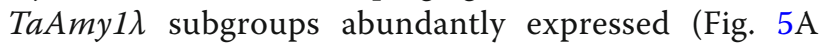
and Fig. 6B, C).

As changes in regulatory sequences affect transcript levels and result in expression divergence in duplicated genes [86], we then compared the 18 promoter sequences (approximately $200 \mathrm{bp}-250 \mathrm{bp}$ upstream of the 'tata' box) from bread wheat and barley. Previous reports indicated both Amy1 and Amy2 genes owned three GA-responsive elements [24, 31, 87]. Both the pyrimidine box and the 'taacaaac' box were conserved between

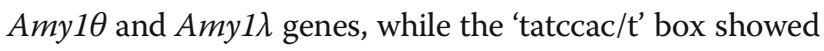
a nucleotide substitution of $\mathrm{C}(A m y 1 \theta)$ to $\mathrm{T}(A m y 1 \lambda)$ (Additional file 10). This substitution was also found in a highly conserved element ('tatccatgcagtg' box) of Amy32b, a representative of low-pI $A m y 2$ gene family [87]. We also sequenced promoter $(1.1 \mathrm{~kb})$ and coding sequences of TaAmy1-A1, TaAmy1-A2 and TaAmy1-D1 from these six investigated wheat lines (Additional file 11), and failed to detect any informative variation associated with this apparent expression divergence. Thus, the regulation mechanisms of the elevated expression levels or activities, as suggested by Farrell et al. [88] and Yang et al. [39], needs to be further uncovered.

\section{Conclusion}

In this study, we present comprehensive analyses of Amy1 genes in wheat and barley. Copy number extension of Amy 1 genes is evident. Under actions of tandem gene duplication and chromosome rearrangement, the original Amy1 locus was divided into two spatially struc-

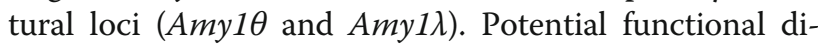
vergence between them is clear according to their sequence mutations and expression differentiations. Genetically, the Amy1 multigene family originates from a single-copy structural locus, and its expansion pattern provides a divergent model during gene duplication and evolution. For agronomical practices, the observed expression differentiation of duplicated copies, and func-

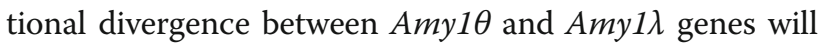
help to better understand the mechanism underlying the dynamic changes of $\alpha$-amylase activity during germination or seed maturation, and provide clues or orientations for dissection of genetic factors impacting $\alpha$-amylase activities in wheat and barley, which will be helpful to further identification of alleles favored for better yield and processing qualities.

\section{Additional files} Additional file 1: Table S1. Primers ( $F$, forward; R, reverse) used in this
study. (DOCX $17 \mathrm{~kb}$ )

Additional file 2: Figure S1. Neighbor-Joining clustering analysis of 125 isolated sequences and 11 full-length copies retrieved from IWGSC WGA v0.4, consisting of 55 isolates from CS (14 TaAmy1-A1; 3 TaAmy1-A2; 3 TaAmy1-B1; 10 TaAmy1-B2; 7 TaAmy1-B3; 9 TaAmy1-D1; 7 TaAmy1-D2; 2 TaAmy1-D3), 19 from PI428191 (9 TuAmy1-A1; 9 TuAmy1-A2; 1 TuAmy1-A3), 18 isolates from PI542268 (2 AesAmy1-B1; 3 AesAmy1-B2; 6 AesAmy 1-B3; 2 AesAmy1-B4; 4 AesAmy1-B5; 1 AesAmy1-B6) and 33 isolates from AS2404 (29 AetAmy1-D1; 1 AetAmy1-D2; 3 AetAmy1-D3). Copies TaAmy1-A3, TaAmy1-B4 and TaAmy1-B5 were failed to isolate, because of lack of enough clones and/or the existence of amplification bias. (TIF $1647 \mathrm{~kb}$ )

Additional file 3: Figure S2. Existence and structure of the truncated copy TaAmy1-B6. (A) Amplification products of TaAmy1-B6 (M marker; 1 CS; 2 PI428191; 3 PI542268; 4 AS2404; 5 N6AT6B; 6 N6AT6D; 7 N6BT6A; 8 N6BT6D; 9 N6DT6A; 10 N6DT6B). (B) The truncated structure of TaAmy1B6. (TIF $31 \mathrm{~kb}$ )

Additional file 4: Table S2. Estimation of Amy1 genetic distances in grass. (DOCX $16 \mathrm{~kb}$ )

Additional file 5: Figure S3. Repeat annotation of intervals between TaAmy $1 \theta$ and TaAmy $1 \lambda$. The identification of repetitive elements was analyzed by using a local BLASTN search against the non-redundant dataset of Triticeae Repeats (http://botserv2.uzh.ch/kelldata/trep-db/ index.html). LTR retrotransposons: Copia (RLC), Gypsy (RLG) and unclassified LTR (RLX); non-LTR retrotransposons: SINE (SIX) and LINE (RIX). DNA transposons: CACTA superfamily (DTC), Mutator superfamily (DTM), PIF/ Harbinger superfamily (DTH), TC1/Mariner superfamily (DTT), hAT superfamily (DTA), MITEs (DXX), Helitron (DHH) and unclassified (DTX), and unclassified elements (XXX). (TIF 648 kb)

Additional file 6: Figure S4. The substitution of Asp233Asn in the SBS1 region. Overall structure of Amy1 was presented in complex with substrate analogues: DAF-BGC and AF1 ligands. Dashed line boxes (from up to down) represented the two starch binding sites: the main active site and the surface binding site (SBS1), respectively. DAF: 4,6-dideoxy-4$\{[(1 \mathrm{~S}, 5 \mathrm{R}, 6 \mathrm{~S})-3-$ formyl-5,6-dihydroxy-4-oxocyclohex-2-en-1-yl]amino\}-a-D-xylohex-5-enopyranose, BGC: $\beta$-D-glucose, AF1: 4,6-dideoxy-4-\{[(1S,4S,5S,6S)- 
4,5,6-trihydroxy-3-(hydroxymethyl)cyclohex-2-en-1-yllamino\}-3-D-glucopyranose. Calcium ions were represented as green balls. Helices were colored in dark cyan, strands in gold, coils in gray and ligands \& C in white. Red arrows represented the two tryptophan residues in SBS1, and the black indicated the Asp233Asn substitution. (TIF $3122 \mathrm{~kb}$ )

Additional file 7: Figure S5. Residual a-amylase activities of ripe wheat grains under three natural conditions. (TIF $550 \mathrm{~kb}$ )

Additional file 8: Table S3. Estimation of duplication and divergence time within groups. (DOCX $17 \mathrm{~kb}$ )

Additional file 9: Figure S6. Length variation of the first intron of 28 Amy1 genes. (TIF $949 \mathrm{~kb}$ )

Additional file 10: Figure S7. Sequence alignment of 18 Amy 1 genes in the promoter region, approximately $200-250$ bp from the 'tata' box. (TIF $399 \mathrm{~kb}$ )

Additional file 11: Promoter and coding sequences of TaAmy1-A1, TaAmy1-A2 and TaAmy1-D1 isolated from six wheat lines. (TXT $51 \mathrm{~kb}$ )

\section{Abbreviations}

BEB: Bayes empirical bayes; CS: Chinese spring; CTAB: cetyl trimethylammonium bromide; DPA: days post anthesis; GA: gibberellic acid; GARE: gibberellic acid response elements; IEF: isoelectric focusing; LMA: late maturity a-amylase; LRT: Likelihood ratio test; MYA: million years ago; NEB: Naive empirical bayes; NT: nullisomic-tetrasomic; PAGE: polyacrylamide gel electrophoresis; PHS: pre-harvest sprouting; pl: isoelectric point; RFLP: restriction fragment length polymorphism; SBS1: starch granule binding surface site; WGD: whole genome duplication

\section{Acknowledgments}

We would like to thank Dr. Mingcheng Luo of University of California, Davis for his constructive advices on the manuscript, Prof. Jirui Wang of Triticeae Research Institute, Sichuan Agricultural University for providing us plant materials; Mr. Yuanzhi Chen and Shun Wang of BaseBio Co. are appreciated for their help on synteny analysis.

\section{Funding}

This work is financially supported by the Major State Basic Research Development Program of China (2014CB138104), and the National S\&T Key Project of China on GMO Cultivation for New Varieties (2016ZX08009-003004-005). The funding bodies played no role in the design of the study and collection, analysis, and interpretation of data and in writing the manuscript.

\section{Availability of data and materials}

All data generated or analysed during this study are included in this published article and its supplementary information files.

\section{Authors' contributions}

$\sqcup J$ conducted experiments, analysed data and wrote the manuscript; GD, JL, $\mathrm{QL}$ and $\mathrm{HZ}$ were responsible for material collection and field phenotype; $\mathrm{HL}$ developed project concept, designed the experiments, and finalized the paper; MY and ZP developed project concept. All the authors have read through the manuscript and agree to the submission of the final version.

\section{Ethics approval and consent to participate}

Not applicable.

\section{Consent for publication}

Not applicable.

\section{Competing interests}

The authors declare that they have no competing interests.

\section{Publisher's Note}

Springer Nature remains neutral with regard to jurisdictional claims in published maps and institutional affiliations.

\section{Author details}

'Chengdu Institute of Biology, Chinese Academy of Sciences, Chengdu 610041, China. ${ }^{2}$ University of Chinese Academy of Sciences, Beijing 100049, China.

Received: 13 September 2018 Accepted: 26 February 2019

Published online: 07 March 2019

\section{References}

1. Chrispeels MJ, Varner J. Gibberellic acid-enhanced synthesis and release of a-amylase and ribonuclease by isolated barley and aleurone layers. Plant Physiol. 1967:42(3):398-406.

2. Jacobsen JV, Scandalios J, Varner JE. Multiple forms of amylase induced by gibberellic acid in isolated barley aleurone layers. Plant Physiol. 1970;45(4):367-71.

3. Gale $M$, Ainsworth $C$. The relationship between a-amylase species found in developing and germinating wheat grain. Biochem Genet. 1984;22(11): 1031-6.

4. Ainsworth C, Doherty P, Edwards K, Martienssen R, Gale M. Allelic variation at a-amylase loci in hexaploid wheat. Theor Appl Genet. 1985;70(4):400-6.

5. Bak-Jensen KS, Laugesen S, Østergaard O, Finnie C, Roepstorff P, Svensson B. Spatio-temporal profiling and degradation of a-amylase isozymes during barley seed germination. FEBS J. 2007;274(10):2552-65.

6. Kuriki T, Imanaka T. The concept of the a-amylase family: structural similarity and common catalytic mechanism. J Biosci Bioeng. 1999;87(5):557-65.

7. Kitajima A, Asatsuma S, Okada H, Hamada Y, Kaneko K, Nanjo Y, Kawagoe Y, Toyooka K, Matsuoka K, Takeuchi M. The rice a-amylase glycoprotein is targeted from the Golgi apparatus through the secretory pathway to the plastids. Plant Cell. 2009;21(9):2844-58.

8. Okamoto K, Kitano H, Akazawa T. Biosynthesis and excretion of hydrolases in germinating cereal seeds. Plant Cell Physiol. 1980;21(1):201-4.

9. Brown A, Jacobsen J. Genetic basis and natural variation of a-amylase isozymes in barley. Genet Res. 1982;40(03):315-24.

10. Gale M, Law C, Chojecki A, Kempton R. Genetic control of a-amylase production in wheat. Theor Appl Genet. 1983;64(4):309-16.

11. Lazarus CM, Baulcombe DC, Martienssen RA. a-Amylase genes of wheat are two multigene families which are differentially expressed. Plant Mol Biol. 1985;5(1):13-24.

12. Huang N, Stebbins GL, Rodriguez RL. Classification and evolution of alphaamylase genes in plants. Proc Natl Acad Sci U S A. 1992;89(16):7526-30.

13. Vallee F, Kadziola A, Bourne $Y$, Juy M, Rodenburg KW, Svensson B, Haser R. Barley a-amylase bound to its endogenous protein inhibitor BASI: crystal structure of the complex at 1.9 å resolution. Structure. 1998;6(5):649-59.

14. Kadziola A, J-i A, Svensson B, Haser R. Crystal and molecular structure of barley a-amylase. J Mol Biol. 1994;239(1):104-21.

15. Robert X, Haser R, Gottschalk TE, Ratajczak F, Driguez H, Svensson B, Aghajari $\mathrm{N}$. The structure of barley a-amylase isozyme 1 reveals a novel role of domain $C$ in substrate recognition and binding: a pair of sugar tongs. Structure. 2003;11(8):973-84.

16. Whittier RF, Dean DA, Rogers JC. Nucieotlde sequence analysis of alphaarnylase and thiol protease genes that are hormonally regulated in barley aleurone cells. Nucleic Acids Res. 1987;15(6):2515-35.

17. Rogers JC, Milliman C. Coordinate increase in major transcripts from the high pl alpha-amylase multigene family in barley aleurone cells stimulated with gibberellic acid. J Biol Chem. 1984;259(19):12234-40.

18. Sargeant J, Walker T. Adsorption of wheat alpha-amylase isoenzymes to wheat starch. Starch-Stärke. 1978;30(5):160-3.

19. Ochiai A, Sugai H, Harada K, Tanaka S, Ishiyama Y, Ito K, Tanaka T, Uchiumi T, Taniguchi M, Mitsui T. Crystal structure of a-amylase from Oryza sativa: molecular insights into enzyme activity and thermostability. Biosci Biotechnol Biochem. 2014;78(6):989-97.

20. Robert X, Haser R, Mori H, Svensson B, Aghajari N. Oligosaccharide binding to barley a-amylase 1. J Biol Chem. 2005;280(38):32968-78.

21. Baulcombe DC, Huttly AK, Martienssen RA, Barker RF, Jarvis MG. A novel wheat a-amylase gene (a-Amy3). Mol Gen Genomics. 1987;209(1):33-40.

22. Whan A, Dielen A-S, Mieog J, Bowerman AF, Robinson HM, Byrne K, Colgrave M, Larkin PJ, Howitt CA, Morell MK. Engineering a-amylase levels in wheat grain suggests a highly sophisticated level of carbohydrate regulation during development. J Exp Bot. 2014;65(18):5443-57.

23. Radchuk W, Borisjuk L, Sreenivasulu N, Merx K, Mock H-P, Rolletschek H, Wobus U, Weschke W. Spatiotemporal profiling of starch biosynthesis and degradation in the developing barley grain. Plant Physiol. 2009;150(1):190-204. 
24. Zhang Q, Li C. Comparisons of Copy Number, Genomic Structure, and Conserved Motifs for a-Amylase Genes from Barley, Rice, and Wheat. Front Plant Sci. 2017:8(1727)

25. Mieog JC, Janeček $\breve{S}$, Ral J-P. New insight in cereal starch degradation: identification and structural characterization of four a-amylases in bread wheat. Amylase. 2017:1(1).

26. Knox CA, Sonthayanon B, Chandra GR, Muthukrishnan S. Structure and organization of two divergent a-amylase genes from barley. Plant Mol Biol. 1987; 9(1):3-17.

27. Huang S, Sirikhachornkit A, Su X, Faris J, Gill B, Haselkorn R, Gornicki P. Genes encoding plastid acetyl-CoA carboxylase and 3-phosphoglycerate kinase of the Triticum/Aegilops complex and the evolutionary history of polyploid wheat. Proc Natl Acad Sci. 2002;99(12):8133-8.

28. Marcussen T, Sandve SR, Heier L, Spannagl M, Pfeifer M, Jakobsen KS, Wulff BB, Steuernagel B, Mayer KF, Olsen O-A. Ancient hybridizations among the ancestral genomes of bread wheat. Science. 2014;345(6194):1250092.

29. Masojć P, Gale M. a-Amylase structural genes in rye. Theor Appl Genet. 1991;82(6):771-6.

30. Khursheed B, Rogers J. Barley alpha-amylase genes. Quantitative comparison of steady-state mRNA levels from individual members of the two different families expressed in aleurone cells. J Biol Chem. 1988;263(35):18953-60.

31. Gubler F, Jacobsen JV. Gibberellin-responsive elements in the promoter of a barley high-pl alpha-amylase gene. Plant Cell. 1992;4(11):1435-41.

32. Rogers JC, Lanahan MB, Rogers SW. The cis-acting gibberellin response complex in high-pl [alpha]-amylase gene promoters (requirement of a coupling element for high-level transcription). Plant Physiol. 1994;105(1):151-8.

33. Gubler F, Kalla R, Roberts JK, Jacobsen JV. Gibberellin-regulated expression of a myb gene in barley aleurone cells: evidence for Myb transactivation of a high-pl alpha-amylase gene promoter. Plant Cell. 1995;7(11):1879-91.

34. Huang N, Koizumi N, Reinl S, Rodriguez RL. Structural organization and differential expression of rice a-amylase genes. Nucleic Acids Res. 1990; 18(23):7007-14

35. Kitajima A, Asatsuma S, Okada H, Hamada Y, Kaneko K, Nanjo Y, Kawagoe Y, Toyooka K, Matsuoka K, Takeuchi M, et al. The rice alpha-amylase glycoprotein is targeted from the Golgi apparatus through the secretory pathway to the plastids. Plant Cell. 2009;21(9):2844-58.

36. Mares DJ, Mrva K. Wheat grain preharvest sprouting and late maturity alpha-amylase. Planta. 2014;240(6):1167-78.

37. Gubler F, Millar AA, Jacobsen JV. Dormancy release. Aba and pre-harvest sprouting. Curr Opin Plant Biol. 2005;8(2):183-7.

38. Mares D, Mrva K. Late-maturity a-amylase: low falling number in wheat in the absence of preharvest sprouting. J Cereal Sci. 2008;47(1):6-17.

39. Yang J, Liu Y, Pu Z, Zhang L, Yuan Z, Chen G, Wei Y, Zheng Y, Liu D, Wang J. Molecular characterization of high pl a-amylase and its expression QTL analysis in synthetic wheat RILs. Mol Breed. 2014;34(3):1075-85.

40. Cheng C-R, Oldach K, Mrva K, Mares D. Analysis of high pl a-Amy-1 gene family members expressed in late maturity a-amylase in wheat (Triticum aestivum L.). Mol Breed. 2014;33(3):519-29.

41. Bolot S, Abrouk M, Masood-Quraishi U, Stein N, Messing J, Feuillet C, Salse J. The 'inner circle'of the cereal genomes. Curr Opin Plant Biol. 2009;12(2):119-25.

42. Vogel JP, Garvin DF, Mockler TC, Schmutz J, Rokhsar D, Bevan MW, Barry K, Lucas S, Harmon-Smith M, Lail K. Genome sequencing and analysis of the model grass Brachypodium distachyon. Nature. 2010;463(7282):763-8.

43. Larkin MA, Blackshields G, Brown N, Chenna R, PA MG, McWilliam H, Valentin F, Wallace IM, Wilm A, Lopez R. Clustal W and Clustal X version 2.0. bioinformatics. 2007;23(21):2947-8.

44. Hall T. A user-friendly biological sequence alignment editor and analysis program for windows TM. Bioedit Version. 1999;7.

45. Hu B, Jin J, Guo A-Y, Zhang H, Luo J, Gao G. GSDS 2.0: an upgraded gene feature visualization server. Bioinformatics. 2014:btu817.

46. Emanuelsson O, Nielsen H, Brunak S, Von Heijne G. Predicting subcellular localization of proteins based on their $\mathrm{N}$-terminal amino acid sequence. J Mol Biol. 2000;300(4):1005-16.

47. Nielsen H, Engelbrecht J, Brunak S, von Heijne G. Identification of prokaryotic and eukaryotic signal peptides and prediction of their cleavage sites. Protein Eng. 1997;10(1):1-6.

48. Kumar S, Stecher G, Tamura K. MEGA7: Molecular Evolutionary Genetics Analysis version 7.0 for bigger datasets. Molecular biology and evolution. 2016:msw054.

49. Tamura K. Estimation of the number of nucleotide substitutions when there are strong transition-transversion and $\mathrm{G}+\mathrm{C}$-content biases. Mol Biol Evol. 1992;9(4):678-87.
50. Jones DT, Taylor WR, Thornton JM. The rapid generation of mutation data matrices from protein sequences. Computer applications in the biosciences: CABIOS. 1992;8(3):275-82.

51. Yang Z, Nielsen R. Estimating synonymous and nonsynonymous substitution rates under realistic evolutionary models. Mol Biol Evol. 2000; 17(1):32-43.

52. Goldman N, Yang Z. A codon-based model of nucleotide substitution for protein-coding DNA sequences. Mol Biol Evol. 1994;11(5):725-36.

53. Yang Z. Likelihood ratio tests for detecting positive selection and application to primate lysozyme evolution. Mol Biol Evol. 1998;15(5):568-73.

54. Wong WS, Yang Z, Goldman N, Nielsen R. Accuracy and power of statistical methods for detecting adaptive evolution in protein coding sequences and for identifying positively selected sites. Genetics. 2004;168(2):1041-51.

55. Yang Z, Wong WS, Nielsen R. Bayes empirical Bayes inference of amino acid sites under positive selection. Mol Biol Evol. 2005;22(4):1107-18.

56. Yang Z. Maximum likelihood estimation on large phylogenies and analysis of adaptive evolution in human influenza virus a. J Mol Evol. 2000;51(5):423-32.

57. Yang Z, Nielsen R. Codon-substitution models for detecting molecular adaptation at individual sites along specific lineages. Mol Biol Evol. 2002; 19(6):908-17.

58. Zhang J, Nielsen R, Yang Z. Evaluation of an improved branch-site likelihood method for detecting positive selection at the molecular level. Mol Biol Evol. 2005:22(12):2472-9.

59. Yang Z. PAML: a program package for phylogenetic analysis by maximum likelihood. Computer applications in the biosciences: CABIOS. 1997;13(5):555-6.

60. Gaut BS, Morton BR, McCaig BC, Clegg MT. Substitution rate comparisons between grasses and palms: synonymous rate differences at the nuclear gene Adh parallel rate differences at the plastid gene rbcL. Proc Natl Acad Sci. 1996;93(19):10274-9.

61. Lynch M, Conery JS. The evolutionary fate and consequences of duplicate genes. Science. 2000;290(5494):1151-5.

62. Wolfe KH, Sharp PM, Li W-H. Rates of synonymous substitution in plant nuclear genes. J Mol Evol. 1989;29(3):208-11.

63. Mount DW: Using the basic local alignment search tool (BLAST). Cold Spring Harbor Protocols 2007, 2007(7):pdb. top17.

64. Li L, Stoeckert CJ, Roos DS. OrthoMCL: identification of Ortholog groups for eukaryotic genomes. Genome Res. 2003;13(9):2178-89.

65. Robert X, Gouet P. Deciphering key features in protein structures with the new ENDscript server. Nucleic Acids Res. 2014;42(W1):W320-4.

66. Marchler-Bauer A, Derbyshire MK, Gonzales NR, Lu S, Chitsaz F, Geer LY, Geer RC, He J, Gwadz M, Hurwitz DI. CDD: NCBI's conserved domain database. Nucleic acids research. 2014, gku1221.

67. Arnold K, Bordoli L, Kopp J, Schwede T. The SWISS-MODEL workspace: a web-based environment for protein structure homology modelling. Bioinformatics. 2006;22(2):195-201.

68. Biasini M, Bienert S, Waterhouse A, Arnold K, Studer G, Schmidt T, Kiefer F, Cassarino TG, Bertoni M, Bordoli L. SWISS-MODEL: modelling protein tertiary and quaternary structure using evolutionary information. Nucleic acids research. 2014:gku340.

69. Bordoli L, Kiefer F, Arnold K, Benkert P, Battey J, Schwede T. Protein structure homology modeling using SWISS-MODEL workspace. Nat Protoc. 2009;4(1):1-13.

70. Kadziola A, Søgaard M, Svensson B, Haser R. Molecular structure of a barley a-amylase-inhibitor complex: implications for starch binding and catalysis. J Mol Biol. 1998;278(1):205-17.

71. Pettersen EF, Goddard TD, Huang CC, Couch GS, Greenblatt DM, Meng EC, Ferrin TE. UCSF chimera - a visualization system for exploratory research and analysis. J Comput Chem. 2004;25(13):1605-12.

72. Bradford MM. A rapid and sensitive method for the quantitation of microgram quantities of protein utilizing the principle of protein-dye binding. Anal Biochem. 1976;72(1-2):248-54.

73. Barrero JM, Mrva K, Talbot MJ, White RG, Taylor J, Gubler F, Mares DJ. Genetic, hormonal, and physiological analysis of late maturity a-amylase in wheat. Plant Physiol. 2013;161(3):1265-77.

74. Chalupska D, Lee H, Faris J, Evrard A, Chalhoub B, Haselkorn R, Gornicki P. Acc homoeoloci and the evolution of wheat genomes. Proc Natl Acad Sci. 2008;105(28):9691-6.

75. Petersen G, Seberg O, Yde M, Berthelsen K. Phylogenetic relationships of Triticum and Aegilops and evidence for the origin of the $a, B$, and D genomes of common wheat (Triticum aestivum). Mol Phylogenet Evol. 2006;39(1):70-82. 
76. Salamini F, Özkan H, Brandolini A, Schäfer-Pregl R, Martin W. Genetics and geography of wild cereal domestication in the near east. Nat Rev Genet. 2002;3(6):429-41.

77. Mascher M, Gundlach H, Himmelbach A, Beier S, Twardziok SO, Wicker T, Radchuk V, Dockter C, Hedley PE, Russell J, et al. A chromosome conformation capture ordered sequence of the barley genome. Nature. 2017;544(7651):427-33.

78. Aoyagi K, Sticher L, Wu M, Jones RL. The expression of barley a-amylase genes inXenopus laevis oocytes. Planta. 1990;180(3):333-40.

79. Salse J, Bolot S, Throude M, Jouffe V, Piegu B, Quraishi UM, Calcagno T, Cooke R, Delseny M, Feuillet C. Identification and characterization of shared duplications between Rice and wheat provide new insight into grass genome evolution. Plant Cell. 2008;20(1):11-24.

80. Zeng X, Long H, Wang Z, Zhao S, Tang Y, Huang Z, Wang Y, Xu Q, Mao L, Deng $G$. The draft genome of Tibetan hulless barley reveals adaptive patterns to the high stressful Tibetan plateau. Proc Natl Acad Sci U S A. 2015;112(4):1095-100.

81. NISHIKAWA K, NOBUHARA M. Genetic studies of a-amylase isozymes in wheat. The Japanese journal of genetics. 1971;46(5):345-53.

82. Cheung W, Chao S, Gale M. Long-range physical mapping of the a-amylase1 (a-Amy-1) loci on homoeologous group 6 chromosomes of wheat. Mol Gen Genet MGG. 1991;229(3):373-9.

83. Zhang J. Evolution by gene duplication: an update. Trends Ecol Evol. 2003; 18(6):292-8.

84. Moore RC, Purugganan MD. The early stages of duplicate gene evolution. Proc Natl Acad Sci. 2003:100(26):15682-7.

85. Cockburn D, Nielsen MM, Christiansen C, Andersen JM, Rannes JB, Blennow A, Svensson B. Surface binding sites in amylase have distinct roles in recognition of starch structure motifs and degradation. Int J Biol Macromol. 2015;75:338-45.

86. Li W-H, Yang J, Gu X. Expression divergence between duplicate genes. Trends Genet. 2005;21(11):602-7.

87. Lanahan $\mathrm{MB}, \mathrm{Ho} \mathrm{T}$, Rogers $\mathrm{SW}$, Rogers JC. A gibberellin response complex in cereal alpha-amylase gene promoters. Plant Cell. 1992;4(2):203-11.

88. Farrell AD, Kettlewell PS, Simmonds J, Flintham JE, Snape JW, Werner P, Jack $\mathrm{PL}$. Control of late maturity alpha-amylase in wheat by the dwarfing gene RhtD1b and genes on the 1B/1R translocation. Mol Breed. 2013;32(2):425-36.

Ready to submit your research? Choose BMC and benefit from:

- fast, convenient online submission

- thorough peer review by experienced researchers in your field

- rapid publication on acceptance

- support for research data, including large and complex data types

- gold Open Access which fosters wider collaboration and increased citations

- maximum visibility for your research: over $100 \mathrm{M}$ website views per year

At $\mathrm{BMC}$, research is always in progress.

Learn more biomedcentral.com/submissions 